\title{
Regional Differences in Attenuation Modelling for Eastern China
}

\author{
H.H. Tsang ${ }^{\mathrm{a}, *}$, M.N. Sheikh ${ }^{\mathrm{b}}$, N.T.K. Lam ${ }^{\mathrm{c}}$, A.M. Chandler ${ }^{\mathrm{d}}$, S.H. Lo ${ }^{\mathrm{a}}$
}

${ }^{a}$ Department of Civil Engineering, University of Hong Kong, Pokfulam Road, Hong Kong, People's Republic of China

${ }^{\mathrm{b}}$ School of Civil, Mining and Environmental Engineering, University of Wollongong, NSW 2522, Australia

${ }^{\mathrm{c}}$ Department of Civil and Environmental Engineering, University of Melbourne, VIC 3010, Australia

d School of Civil Engineering and the Environment, University of Southampton, Highfield, Southampton SO17 1BJ, United Kingdom

* Corresponding author. Tel.: +852-28591970; fax: +852-25595337.

E-mail address: tsanghh@hku.hk (H.H. Tsang). 


\begin{abstract}
This paper describes the development of seismological models for three sub-regions within Eastern China. An important feature of the modelling is that two main types of local data were used to determine parameters for input into the seismological model. Shear wave velocity data was used in Step One of the procedure for deriving the upper crustal factors which are part of the seismological model. Two further steps were involved in incorporating the historical Intensity $(M M I)$ data into the modelling. In Step Two, the simulated peak ground velocity $(P G V)$ values were converted to $M M I$ values, and site factor was calculated by dividing the inferred $P G V$ value by the respective simulated $P G V$ value for each given (short distance) earthquake scenario. In Step Three, the quality $(Q)$ factor of the seismological model for each sub-region was calibrated in accordance with the criterion that site factors inferred from records of long distance earthquakes in the database match with the median site factor obtained in Step Two for short distance earthquakes. Importantly, the $Q$ values obtained by this calibration method were highly consistent with Coda $Q$ values (obtained for each sub-region from a previous study by Jin and Aki based on analysing records of local earth tremors). The calibrated $Q$ values in combination with the developed crustal factors and geometrical attenuation factor constitute the regional seismological model for Eastern China. The seismological model so developed takes into account intra-regional differences and has been used to simulate strong ground motions by the stochastic method for assessing the potential seismic hazards in the region.
\end{abstract}

Keywords: Seismological model; Attenuation; Quality $(Q)$ factor; Soil site; Intensity; Eastern China 


\section{Introduction}

Considerable research has been devoted to the development of reliable ground motion response spectra for the design of new structures and the assessment of existing structures. In well instrumented regions of high seismicity where strong ground motion data are in abundance, like California, most attenuation relationships were developed from regression of recorded ground motion parameter such as peak ground accelerations, peak ground velocities and response spectral accelerations. Examples of such empirical relationships have been developed by Sadigh et al. (1997), Abrahamson and Silva (1997) and Ambraseys et al. (1996).

The alternative approach of ground motion modelling which is suited to inner continental regions of low to moderate seismicity is stochastic simulations of the seismological model. The frequency content of ground motions so simulated by the procedure is constrained by the theoretical framework of the seismological model (Boore, 1983). Rigorous seismological monitoring studies have been undertaken in Central and Eastern North America (CENA) to evaluate individual factors in the seismological models that are specific to conditions of the region. Regional specific factors that have been evaluated include the source factor (e.g. Atkinson, 1993), quality $(Q)$ factor of whole path wave transmissions (e.g. Atkinson and Mereu, 1992) and upper crustal amplification and attenuation factors (e.g. Boore and Joyner, 1997; Atkinson and Silva, 1997). The seismological models so developed for CENA have been used for generating accelerograms that are representative of the seismological characteristics of the CENA region. Finally, attenuation relationships were obtained by regression of ground motion parameters calculated from the stochastically simulated accelerograms. Examples of attenuation relationships that have been developed by this approach have been presented by Atkinson and Boore (1997), Toro et al. (1997) and Dahle et al. (1990). An overview of the seismological model is given in Section 2. 
This paper is concerned with the derivation of attenuation relationships that are representative of Eastern China. The seismicity of Eastern China is dominated by the Tanlu fault system which crosses the eastern part of Northern China. The Tanlu fault system extends into the tectonic regions of Northeastern China up to Russia (Xu et al., 1987; Deng, 1995; Xu and Deng, 1996). In a recent study on the time-dependent seismicity in China, the overall seismic activity in Eastern China has been observed to be "low" to "moderate" (Qin et al., 2001). The current seismic zoning map for the whole of China was computed based only on two ground motion attenuation models: one representing Eastern China and the other representing Western China (Gao, 2003). Differences in geological settings within the region, however, have not been fully reflected in the previous seismic hazard studies for Eastern China. Such differences are important for modelling response spectra for long distance earthquakes. A much more rigorous modelling methodology that accounts for the conditions of bedrock and surface sediments is thus crucial for future seismic zonation for Eastern China.

Whilst Eastern China is lacking in instrumented strong motion data that are representative of local conditions, there is an abundance of historical macro-seismic (Intensity) data from the region which could be used for supporting the development of representative attenuation relationships. In addition, the study by Jin and Aki (1988) on $Q$ factors in the region serves as an important reference for the determination of the respective factor in the seismological model. The contour map of Coda $Q$ values developed by Jin and Aki is shown in Fig. 1 for the three geological sub-regions of Eastern China: (i) The Sino-Korean Paraplatform (SKP), (ii) The Yangzi Platform (YZP) and (iii) The South China Fold System (SCF). Valuable local information is also available for constraining the shear wave velocity profile of the earth crust which can be used for estimating the crustal amplification and attenuation factors in the seismological model.

However, little is known of the source characteristics of earthquakes in Eastern China. Consequently, in this study, the source factor of Atkinson (1993) derived for CENA 
was "imported" for input into the seismological model. There are also uncertainties of whether the Coda $Q$ values recommended by Jin and Aki (1988) based on seismological monitoring of Coda waves from local earthquake tremors are representative of conditions of large magnitude earthquakes (which can be from a long distance). These uncertainties present a challenge to seismological modelling for the region. The seismological model for Eastern China could not be developed from scratch in the same way the seismological models for CENA were developed because of the lack of locally recorded ground motion data.

In addressing the challenge, a hybrid seismological modelling approach which makes effective use of Intensity data was adopted in developing attenuation relationships for the three major sub-regions within Eastern China. The modelling procedure so adopted is briefly described in the following:

First, seismological parameters, namely the upper crustal amplification and attenuation parameters, which characterize the path modification (transmission) behaviour of short distance earthquakes $(\mathrm{R}<50 \mathrm{~km})$, were first evaluated. Seismological modelling for short distance earthquakes was more straightforward than long distance earthquakes given that ground motion parameters associated with short distance earthquake events $(\mathrm{R}<50 \mathrm{~km})$ were insensitive to the assumed value of $Q$ (which controls anelastic attenuation) and the crustal thickness of the earth crust (which controls geometrical attenuation at long distances). This first step of the modelling is described in Section 4.1.

Second, the Intensity database for each sub-region was partitioned into two groups: (i) short distance $(\mathrm{R}<50 \mathrm{~km})$ and (ii) long distance $(\mathrm{R}>50 \mathrm{~km})$. Site factors (from rock to "average" soil sites) for each sub-region can be estimated based on the comparison of parameters derived from stochastic simulations of the seismological model developed for short distance earthquakes (which represents conditions on rock) with parameters inferred from the short distance Intensity data (which represents conditions on average soil sites). Importantly, the values of the site factor so estimated 
from the comparison were generally consistent within the database of short distance earthquakes that have been incorporated into the study. The observed consistency with the estimated site factor serves as a holistic check of the developed seismological parameters that are relevant to the behaviour of short distance earthquakes. This second step of the modelling procedure is described in Section 4.2.

Third, similar comparisons for long distance earthquakes were made for each subregion. A wide range of $Q$ factors were assumed in the simulations. With every $Q$ factor assumed in a simulation, there was always a corresponding (inferred) median site factor. In every simulation, the $Q$ factor was calibrated in accordance with the criterion that the site factor inferred from the records of long distance earthquakes matched with that of short distance earthquakes (as obtained in Step One). This third step of the modelling procedure is described in Section 5.3. The implicit assumption with this calibration approach was that the site factor for short distance and long distance earthquakes would be similar for any given sub-region. The $Q$ factors so calibrated for the three sub-regions were consistent with estimates provided previously by Jin and Aki (1988) based on analysis of Coda waves recorded from local earth tremors. This consistency again re-assures the credibility of the developed seismological model and the resulting attenuation relationships.

Recordings from the 1976 M7.7 Tangshan earthquake were used to test the seismological model providing additional assurances. This final (validating) step for verifying the developed seismological models based on comparison of the simulated results with those recorded in the field is described in Section 6. The potential significance of the developed seismological model will be discussed in Section 7 , followed by conclusions in Section 8 .

This study is based mainly on comparing ground motion parameters ( $P G V$ values) inferred from Intensity data for historical events occurred in the region with parameters obtained from stochastic simulations of the developed seismological models. Whilst verification of the seismological model is best undertaken by 
comparison of the recorded and simulated accelerograms and response spectra, such direct verification is impossible for Eastern China because of the lack of representative instrumental data.

\section{Overview of seismological model}

The seismological model was originally developed by Brune (1970), and subsequently studied and further extended by Boore (1983), Atkinson (1993), Atkinson and Boore $(1995,1998)$ and Atkinson and Silva (1997). In the seismological model, the Fourier amplitude spectrum $A_{X}(f)$ of seismic waves reaching the exposed surfaces of rock can be expressed as the product of a number of regional and local factors, as defined by Eq. (1):

$$
A_{X}(f)=S(f) G \operatorname{An}(f) \operatorname{Va}(f) P(f)
$$

where $S(f)$ is the regional, and generic, source factor, $G$ the regional geometric attenuation factor, $\operatorname{An}(f)$ the regional anelastic whole path attenuation factor, $\operatorname{Va}(f)$ the local upper crust amplification factor, and $P(f)$ the local upper crust attenuation factor. It is noted that soil site effects have not been taken into account.

The seismological model defined by Eq. 1 was used for generating ground motion time-histories using the stochastic approach (Boore, 1983). Windowed and bandlimited white noises were first generated and then modulated in the frequency domain by the function of the seismological model. The ground motion time-histories were then obtained by inverse Fourier transform of the modulated motions. Detailed descriptions of the regional and local factors of the seismological model and the stochastic simulation methodology can be found in Lam et al. (2000).

\subsection{Regional factors}


Regional, and generic, source factor $S(f)$ has been used to generalise the average behaviour of seismic waves generated at the source of the earthquake to the whole region. The source factor adopted in this study is characterised by two-corner frequencies and was originally developed in Atkinson (1993) for modelling ground motions in CENA. This is distinguished from the well known omega-square source model of Brune (1970), which is characterised by a single corner frequency. This source factor has subsequently been employed for modelling ground motions in Australia (Lam et al., 2006), South China (Lam et al., 2002; Chandler et al., 2006b), Singapore (Balendra et al., 2002), Tehran, Iran (Yaghmaei-Sabegh and Lam, 2009) and the distant effects of Gujarat earthquake in India (Chandler and Lam, 2004). The good agreement of the modelled ground motions with records and field observations from historic and recent earthquake events occurring in these regions support the generalisation of the model to all stable continental regions of low to moderate seismicity including the Eastern China region.

The geometrical $(G)$ factor represents the attenuation of the amplitude of the radiated seismic waves resulting purely from the geometrical spread of energy (as opposed to dissipation of energy). The $G$-factor in the near field conforms to spherical attenuation and is independent of regional conditions. It becomes regionally dependent in the farfield where the attenuation pattern is influenced significantly by seismic waves reflected from the Moho discontinuity, which defines the interface between the earth crust and underlying lithosphere. More detailed descriptions of the $G$-factor can be found in Lam et al. (2000).

\subsection{Regional whole path anelastic attenuation factor}

Whole path attenuation is particularly important in the modelling of ground shaking from distant earthquakes (Chandler and Lam, 2004), which is the main focus of this study. Large-magnitude earthquakes generated at source-site distances $(R)$ exceeding $100 \mathrm{~km}$ are typified by low-frequency (long-period) seismic waves, since the high- 
frequency components have greatly diminished in amplitude as a result of energy absorption along the source-site wave transmission path. The peak ground acceleration $(P G A)$ from such distant earthquakes can be very low and yet the induced ground motions can be disproportionately destructive due to its high displacement and velocity shaking characteristics, which result from medium- and long-period waves that are relatively robust to anelastic attenuation along the wave transmission path.

Whole path attenuation is a regional mechanism and must be distinguished from the (local) attenuation of the upper crust or (site) attenuation within the overlying soil sediments. The attenuation mechanism may be characterized by the value of the seismological $Q$ factor (equivalent to $Q_{0}$, namely $Q$ at frequency of $1 \mathrm{~Hz}$ ) as obtained from seismological monitoring in the region. The value of $Q$ may be substituted into Eq. (2) for developing the filter function $A n(f)$ which represents the effects of whole path attenuation of seismic waves propagating within the earth crust.

$$
A n(f)=e^{-\cdot \frac{\pi \cdot f \cdot R}{Q(f) \cdot V_{s}}}
$$

where $f$ is the wave frequency, $R$ is the length of the wave travel path and $V_{s}$ is the shear wave velocity $(S W V)$. The $Q(f)$ function is defined by:

$$
Q(f)=Q_{0} f^{\eta}
$$

Substitution of Eq. (3) into Eq. (2) yields the estimated whole path attenuation factor.

\subsection{Local upper crustal amplification and attenuation factors}

Upper crustal amplification $\operatorname{Va}(f)$ and attenuation $P(f)$ mechanisms occurring in approximately the upper $4 \mathrm{~km}$ of the earth crust can be considered as local mechanisms. The study of near-field earthquakes by Abercrombie (1997) based on instrumentation of deep drill-holes in California identified that filtering mechanisms occurring within this depth range accounted for some $90 \%$ of the total modifications of the seismic waves along their wave-transmission path within the rock crust. The 
size of the sub-region which is covered by a set of local factors would depend on the amount of available geological and geophysical data. In the context of this study on Eastern China, the amount of data available resulted in the region being resolved broadly into three sub-regions. Should more data become available, a regional attenuation model based on a finer division of the sub-regions each having its own set of local factors can be achieved. An example of such finer divisions can be found in Chandler et al. (2006b).

\section{Earthquake Intensity database}

Written earthquake records in China can be obtained for four thousand years and the earliest recorded earthquake was in 1831 B.C. In the Ming and Qing dynasties, there were more than two thousand counties and the data recorded during that time formed the basic historical earthquake database in China. In the 1960's, the Chinese government organized a group of historians and earthquake specialists to search through all the dependable literature and collect historical earthquake records, in order to compile a chronological table of historical earthquakes occurred in China. The records are of high scientific value for seismological research.

A large number of historical earthquake events have been collected, for the purpose of this study, from a number of sources including the China Earthquake Yearbook (1949 - 1981) (Gao, 1990), Catalogue of Chinese Earthquakes (1831 B.C. - 1969 A.D.) (Gu, 1989), and the database of Guangdong Seismological Bureau. Earthquake events occurred in Eastern China with magnitude greater than 5, which have been used in this study, have been superimposed onto Fig. 1. Most earthquake events $(M>5)$ in these regions occurred in Hebei province, whilst other events occurred mostly in Shanxi, Henan, Shaanxi, Shandong, Hubei, Anhui and Jiangsu provinces.

The data used in the present analyses are 131 historical earthquake records of Eastern China with 298 isoseismal (summarised in Table 1). Each isoseismal is parameterised 
by two parameters, $\mathrm{Ra}$ and $\mathrm{Rb}$, which are the horizontal radii taken along the long and short axes respectively. The average horizontal radius, $R v$, where $R v=\sqrt{ }(R a R b)$, which is the epicentral distance, can then be calculated for each isoseismal. In this study, the average horizontal radius is adopted to represent the average rate of Intensity attenuation in all orientations. In the rest of this paper, this averaged radius is referred simply as "distance". The magnitude-distance combinations for the historical $M M I$ values that have been identified and used for analyses in this study are presented in Figs. 2(a)-2(c). Meanwhile, details of all isoseismals, together with the values of the three radii, summarised separately for the three sub-regions, are presented in Appendix A. Note, historical earthquake records provide no information on soil site effects.

\section{Seismological modelling for short distance earthquakes $(R<50 \mathrm{~km})$}

\subsection{Step one: Local upper crustal factors}

In this section, seismological parameters dominating the path modification behaviour of short distance earthquakes in the area are evaluated to fulfil the first step of the modelling procedure as outlined in the Introduction.

Upwardly propagating seismic shear waves are amplified when crossing from a medium of higher shear wave velocity to that of lower shear wave velocity (a phenomenon that can be explained by the principles of conservation of energy). Upper-crustal amplification is a function of the $S W V$ profile of the earth crust, particularly at shallow depths and is dependent on the frequency of the transmitted waves. In parallel with the amplification mechanism in the upper crust is the attenuation mechanism. Both mechanisms occur within a short transmission distance in the upper crust. To develop representative upper crustal factors representing these two mechanisms, the $S W V$ profile for each of the average geological formations in the three regions must be accurately modelled. 
At shallow depths within the reach of drillholes, longitudinal wave travel time was measured to determine the compressional modulus, which was then used for calculating the shear modulus based on the estimated Poisson's ratio. An empirical formula has been developed in Chandler et al. (2005a) for converting velocity of longitudinal waves into that of shear waves. Useful supplementary information on the $S W V$ of weathered rock has also been obtained by relating the reported rock classification with in-situ test results. At greater depths of up to $8 \mathrm{~km}, S W V$ data can be obtained from the literature (e.g. Feng et al., 1981, Li and Mooney, 1998) which reports on observations from seismological monitoring studies.

A generalised framework for modelling the $S W V$ profile (with depth) has been developed recently in Chandler et al. (2005a). The modelling framework enables $S W V$ profile of an area to be predicted from information reported in CRUST2.0 (Laske et al., 2000). The information is then augmented by velocities of longitudinal and shear waves recorded directly in the field. In summary, the $S W V$ profile of the earth crust, comprising the sedimentary and the crystalline crustal rock layers, may be approximated by a tri-linear model (in most cases) comprising three straight lines (with velocity and depth plotted in logarithmic scales).

This generic $S W V$ profile may be characterized rather simply by the following three regional parameters and one local parameter:

1. Depth parameter $Z_{c}(\mathrm{~km})$ which defines the total thickness of the sedimentary rock layers, and is the depth measured to the top of the crystalline crustal layers, and can be determined directly from CRUST2.0;

2. Depth parameter $Z_{s}(\mathrm{~km})$ which forms part of the bi-linear model for the sedimentary rock layers, and has been shown from case studies to be in the order of $1 / 3$ of the value of $Z_{c}$;

3. Mid-crust velocity $V_{s, 8}(\mathrm{~km} / \mathrm{s})$ which is defined at a representative depth of $8 \mathrm{~km}$ measured from the rock surface (or $Z_{c}$ plus $4-6 \mathrm{~km}$ ) which is typical of the 
seismogenic (source) depths for moderate to large crustal earthquakes, and can be inferred from information provided by CRUST2.0;

4. Local near-surface velocity $V_{s, 0.03}(\mathrm{~km} / \mathrm{s})$ at depth $Z=0.03 \mathrm{~km}(30 \mathrm{~m})$ which can be measured directly in the field for comparison with information inferred from CRUST2.0.

The four modelling parameters that have been identified for the three sub-regions are listed in Table $2 \mathrm{a}$ and the corresponding $S W V$ profiles listed in Table $2 \mathrm{~b}$. The proposed $S W V$ profiles together with the published data for the three selected subregions are presented in Figs. 3(a)-3(c) and Figs. 4(a) and 4(b) for comparison with the reference model $S W V$ profiles for generic "rock" and "hard rock" representing conditions of WNA and CENA respectively (Boore and Joyner, 1997). It is shown that the upper few hundreds meters of the three regional $S W V$ profiles for Eastern China are very similar and they are all bounded in between the generic profiles.

The $S W V$ profiles so derived for the three sub-regions were used for calculating the upper crustal amplification factor $\mathrm{Va}(f)$ using the quarter-wave-length method described in Boore and Joyner (1997). Meanwhile, the co-existing upper crustal attenuation factor $P(f)$ was calculated based on a kappa $(\kappa)$ factor derived according to the methodology proposed in Chandler et al. (2005b, 2006a), which correlates $\kappa$ with the near surface $S W V$ of rock. The $G$-factor for short distance earthquakes (R < $50 \mathrm{~km})$ is simply $1 / \mathrm{R}$. The whole path anelastic attenuation factor, $A n(f)$, is insignificant for earthquakes within a distance of $50 \mathrm{~km}$ and hence omitted in the simulations. The adopted source factor, $S(f)$, was based on recommendations by Atkinson (1993) for CENA. All these factors including the crustal factors evaluated from the study were substituted into Eq. (1), the seismological model, which defines the frequency contents on rock for short distance earthquakes in Eastern China.

\subsection{Step two: Inferred site factors}


The seismological model so developed was then used for stochastic simulations of the accelerograms which were used in turn for estimating the $P G V$ values on rock sites. Meanwhile, $P G V$ values have also been inferred from historical $M M I$ data making use of the well known relationship of Eq. (4) (Newmark and Rosenblueth, 1971) for conversion from $M M I$ to $P G V$.

$$
2^{M M I}=1.4(P G V)
$$

It is noted that several other $M M I-P G V$ conversion equations are available in the literature. The adopted $M M I-P G V$ relationship (Eq. 4) has been validated by comparison with numerous other relationships in Lam et al. (2003). The comparison shows significant discrepancies in the estimated Intensity values that were based on different Intensity scales being used. However, importantly, the slopes of the MMI$P G V$ correlations were highly consistent across studies carried out in different regions using different Intensity scales (Lam et al., 2003).

The key outcome from this first step of the modelling procedure was in comparing the $P G V$ values simulated for rock sites with the $P G V$ values inferred from the historical Intensity data for the average soil sites. As soil site effects have not been accounted for by the stochastic simulations of the seismological model (which is about simulating ground motions on rock), the average soil site effects were taken as the average difference between the Intensity inferred $P G V$ values and the stochastically simulated $P G V$ values for the same earthquake scenario. In other words, the ratio of the two $P G V$ values is defined herein as the inferred site factor. The path effects are negligible if the source-site distance is shorter than $50 \mathrm{~km}$. So, it was decided to use recorded $M M I$ historical data, with isoseismal radii ranging from 20 to $50 \mathrm{~km}$, for obtaining the inferred (median) site factors which were calculated separately for each sub-region, in order that differences of the upper crustal properties, though small, have been taken into account. A summary of the statistics of the inferred site factors calculated for each of the three sub-regions is shown in Table 3. Average site factors in the range of 1.5-1.8 have been estimated. 
Frequency-dependent crustal amplification factors have been reported in Boore and Joyner (1997) for generic "rock" sites (of WNA), generic "hard rock" sites (of CENA) and generic "soil" sites. It was reported that the total crustal amplification factor ranges between 1.42 and 2.25 for generic "rock" sites; 1.07 and 1.13 for generic "hard rock" sites; and 2.24 and 2.95 for generic "soil" sites over the frequency range of engineering interests which is in the order of $0.5 \mathrm{~Hz}$ to $3 \mathrm{~Hz}$. The site amplification factors for the two crustal conditions can be inferred by dividing the reported total crustal amplification factors for "soil" by the respective factors for "rock" or "hard rock". For example, it can be shown that the site factor (soil/rock) of WNA is between 1.3 and 1.6 (mid-range at 1.45) and the site factor (soil/hard rock) of CENA is between 2.1 and 2.6 (mid-range at 2.3). Both conditions in WNA and CENA can be described as extreme conditions which have been identified with a median inferred site factor of 1.45 and 2.3 respectively. It is noted that the median value of 1.45 is only some $10 \%$ different to the lower and upper bound values of 1.3 and 1.6; likewise, the median value of 2.3 is also only some $10 \%$ different to the respective lower and upper bound values of 2.1 and 2.6. There is indeed an element of frequency dependence in the site factor but the difference is not large and hence the variation of the site factor with epicentral distance has not been parameterized in this study. Furthermore, the site factors of 1.5 to 1.8 so estimated in this study for the three subregions of Eastern China are all within the range of site factors inferred for the "rock" and "hard rock" conditions in North America as quoted above.

\section{Seismological modelling for long distance earthquakes $(R>50 \mathrm{~km})$}

\subsection{Significance of $Q$-factors}

The significance of anelastic whole path attenuation has been confirmed by the series of analyses presented in this section, especially for far-field events having source-site distance $(\mathrm{R})$ greater than $100 \mathrm{~km}$. Also, the regional differences of the crustal structures of the three selected regions, indicated by Jin and Aki (1988), have been re- 
confirmed by historical earthquake $M M I$ data, using a seismological modelling approach. Moreover, this study indicates the potential underlying difference in response spectrum modelling from the engineering point of view, for which design response spectra would be calculated (refer Section 7) for some scenario near-field and far-field earthquake events.

Fig. 5 shows the comparison of $M M I$ attenuation relationships (for $\mathrm{M}=7$ ) for the three sub-regions of Eastern China (without soil site effect). Results were obtained from the stochastic simulations of the seismological model. The typical crustal thickness of the three sub-regions, obtained from the global database CRUST2.0, is $31 \mathrm{~km}$. The $Q$ values assumed for this comparison of $M M I$ attenuation relationships were 200 for SKP, 600 for YZP and 350 for SCF. These values are based on recommendations by Jin and Aki (1988). The source factor and the upper crustal factors are the same as those used in simulating short distance earthquakes. The conversion relationship of Eq. (4) was used in developing the predictions.

As shown in Fig. 5, the difference between the rates of attenuation is mainly due to the combination of a number of path transmission mechanisms, as described in the previous sections, including $G, \operatorname{An}(f), \operatorname{Va}(f)$ and $P(f)$. The crustal thickness is taken to be uniform across the entire region. Intra-regional differences with attenuation characteristics due to influences by the upper crustal structure are considered as negligible. It is observed from Fig. 5 that the difference in attenuation rate is not significant for the distance range within $50-100 \mathrm{~km}$. However, the difference becomes increasingly significant with longer distances. Such differences with long-distance attenuation are contributed mostly by intra-regional variations in the wave transmission qualities of the earth crust (i.e. anelastic whole path attenuation) which is characterized by the crustal $Q$ factor.

\subsection{Quality factors from contour map of Jin and Aki}


The three seismogenic sub-regions that have been studied were identified from intraregional variations in the wave transmission quality of the earth crust within Eastern China. A map of Coda $Q$ at $1 \mathrm{~Hz}\left(Q_{0}\right)$, herein termed simply $Q$, was proposed by Jin and Aki (1988) for the territory of China. Fig. 1 is a reproduction of the map published in that article for Eastern China.

The first sub-region studied is SKP and is characterized by an earth crust with lower values of $Q$ (where the typical $Q$ value is around 100-300) and is comparable to the crustal properties of Western North America (WNA). It is observed that most earthquake events in SKP occurred along the $Q=200$ contour line. The second subregion is characterized by an earth crust with higher $Q$ values (in the order of $400-$ 1000) which is comparable to the crustal properties of CENA in which the value of $Q$ is typically around 600-700. This sub-region is located inside YZP. The third subregion forms part of SCF, for which the typical $Q$ value is in the order of 250-400 (Jin and Aki, 1988, Mak et al., 2004). It can be observed that areas with higher $Q$ values tend to have experienced relatively lower level of seismic activity, which is consistent with what was reported by Jin and Aki (1988).

It is interesting to observe that, in the depth range $400 \mathrm{~m}-4 \mathrm{~km}$, the $S W V$ profile of SKP (with typical $Q$ values of 100-300) is comparable to that of WNA (with typical $Q$ values of 180), whereas the $S W V$ profile of YZP (with typical $Q$ values of $400-$ 1000 ) is more comparable to that of CENA (with typical $Q$ values of 680). On the other hand, SCF is characterized by the value of $Q$ varying in between 250 and 400 , and its $S W V$ profile lies in between that of CENA and WNA. This independent piece of information provides further support for the assumed typical $Q$ values and the $S W V$ profiles constructed. This observation is also consistent with the findings by Chandler et al. (2006a), in which a correlation between $Q$ values and $S W V$ parameters of the upper crust has been developed from a global database.

\subsection{Step three: Quality factors from calibration}


Whilst $Q$ values have been estimated by Jin and Aki (1988) from analysis of Coda waves recorded from local tremors for the three sub-regions within Eastern China, it was uncertain if these $Q$ values would be representative of conditions of large magnitude earthquakes. The next step in the modelling procedure is to make inferences of the probable values of $Q$ from historical $M M I$ data for long distance earthquakes (i.e. where the isoseismal radius exceeds a certain value, which might be considered sufficient to show a significant regional difference in the path effects). The crustal conditions in SCF and YZP, is considered of higher quality (i.e. higher $Q$ values) as indicated by Jin and Aki (1988) in comparison to conditions in SKP. Hence, isoseismals with radii greater than $100 \mathrm{~km}$ were employed in the inference analysis for the SCF and YZP regions, whereas isoseismals with radii greater than $50 \mathrm{~km}$ were employed in the analysis for the SKP region.

$Q$ was made the sole parameter to vary in the parametric studies. With every assumed value of $Q$, there was always a corresponding inferred median site factor. As the value of $Q$ was varied, the resulting change in the value of the inferred median site factor is indicated by the "hollow circle symbols" in Figs. 6(a)-6(c) (and the associated 90\% confidence limits by the error bars). For each sub-region, the value of $Q$ was calibrated in accordance with the criterion that the inferred site factor for long distance earthquakes matched with the value evaluated in Section 4.2 for short distance earthquakes. The most probable ranges of $Q$ values have been determined using this calibration approach for each sub-region.

The median site factors inferred for short distance earthquakes in Section 4.2 (as summarised in Table 3) are shown again in Figs. 6(a)-6(c) as horizontal solid lines (and the associated 90\% confidence limits as horizontal dashed lines). For the SKP sub-region [refer Fig. 6(a)], the inferred median site factor on the $M M I$ scale is 0.85 and the corresponding $90 \%$ confidence interval is $0.85+/-0.15$, i.e. $0.70-1.0$. This is translated into a median site factor of $1.8\left(=2^{0.85}\right)$ and lower and upper $90 \%$ confidence limits of 1.6 and 2.0 respectively. Meanwhile, the median site factor 
inferred for long distance earthquakes $(\mathrm{R}=50-500 \mathrm{~km}$ ) is shown (by symbols in Fig. 6(a) to vary in between $2.1\left(=2^{1.05}\right)$ for $Q=100$ and $1.3\left(=2^{0.4}\right)$ for $Q=500$. The sensitivity of long distance ground motions to the $Q$ value is evident and points to the importance of their accurate determination. Results from this calibration analysis shows that the most probable range of $Q$ would be in the order of $120-280$, with a most likely value of 200, which is in excellent agreement with estimates by Jin and Aki (1988).

Similarly for the YZP sub-region [refer Fig. 6(b)], the site factor inferred for short distance earthquakes in the sub-region on the $M M I$ scale is 0.65 and the corresponding $90 \%$ confidence interval be $0.65+/-0.23$, i.e. $0.42-0.88$. This is translated into a median site factor of $1.6\left(=2^{0.65}\right)$ and lower and upper $90 \%$ confidence limits of 1.3 and 1.8 respectively. The relatively lower level of confidence, compared to the cases of SKP and SCF, is due to the smaller number of historical MMI data available for the YZP sub-region. Meanwhile, the median site factor inferred for long distance earthquakes $(\mathrm{R}=100-400 \mathrm{~km})$ varies in between $2.1\left(=2^{1.07}\right)$ for $Q=350$ and 1.6 $\left(=2^{0.65}\right)$ for $Q=600$. Thus, a reasonable value of $Q$ for the sub-region would be greater than 450, and the best estimate would be around 600, which is in agreement with the typical value estimated by Jin and Aki (1988). Given that the inferred site factor becomes insensitive to the value of $Q$ when its value exceeds 600, a cap of $Q=$ 600 is applied to areas in YZP where $Q$ exceeds 600 (as shown in Fig. 1 in Jin and Aki, 1988). Simulation results further demonstrate the importance of determining an accurate $Q$ value, as for example, if a $Q$ value of around 300 was employed in YZP, a reduction of $M M I$ of 0.55 unit could result, which is translated into more than $45 \%$ under-estimation of the $P G V$ values.

For the SCF sub-region [Fig. 6(c)], the median site factor inferred for short distance earthquakes in the sub-region on the MMI scale is 0.58 and the corresponding $90 \%$ confidence interval is $0.58+/-0.11$, i.e. $0.47-0.69$. This is translated into a median site factor of $1.5\left(=2^{0.58}\right)$ and lower and upper $90 \%$ confidence limits of 1.4 and 1.6 
respectively. The site factor inferred for long distance earthquakes ( $R=100-300 \mathrm{~km})$ in the sub-region varies in between $2.0\left(=2^{1.0}\right)$ for $Q=150$ and $1.2\left(=2^{0.25}\right)$ for $Q=500$. Results from the calibration analysis show that a most probable range of the value of $Q$ in the sub-region would be in the order of $260-360$, with a most likely value of around 320.

The calibrated $Q$ values so obtained in this study are listed in Table 4 along with the Coda $Q$ values shown on the contour map of Jin and Aki (1988). The good consistency between the two sets of $Q$ values which were developed independently for the sub-regions supports the use of Coda $Q$ values in representing conditions of large magnitude long distance earthquakes. The validity in these $Q$ values being incorporated into the seismological model is re-assured. Hence, these $Q$ values have been substituted into Eq. (2) and Eq. (3) for the calculation of the respective anelastic attenuation factors. Finally, the full set of seismological parameters for characterising the attenuation behaviour for each sub-region were obtained by combining the generic source factor with the crustal factors evaluated in Section 4 and the anelastic and geometrical attenuation factors evaluated in Section 5. Table 5 provides a summary of the seismological parameters for the three sub-regions that are being studied.

\section{Comparison with recorded data}

This section describes the final (confirmatory) step in the modelling procedure. First, the Intensity values simulated by the developed seismological model for the three subregions within Eastern China are compared with Intensity values recorded on Isoseismal maps (Section 6.1). A further check of the simulations was undertaken by comparing the Intensities recorded from the 1976 Tangshan earthquake with those simulated by the seismological model developed for SKP where Tangshan is located (Section 6.2). In Section 6.3, attenuation relationships derived from the developed seismological models have also been compared with existing attenuation model developed for Eastern China (Wang et al., 2000). 


\subsection{Comparison with recorded Intensities of historical earthquake events}

All historical earthquakes collected were simulated using the seismological models developed in previous sections (in which the calibrated $Q$ values were amongst the parameters that have been input into the model). The $P G V$ values calculated from the simulated accelerograms were then converted into $M M I$ values using Eq. (4). The simulated $M M I$ values (having been corrected for site effects) were compared with values inferred from the isoseismal maps. The two sets of $M M I$ values associated with the three sub-regions are correlated in Figs. 7(a)-7(c). Significantly, no overall biases are shown with the correlations although there are considerable scatters which are believed to be contributed by the following uncertainties: (i) uncertainties in the quality of the surveyed structures which have sustained damage; (ii) uncertainties in the correlation between the level of damage to the structure and the ground motion parameter; (iii) uncertainties in the site conditions and (iv) uncertainties in the interpretations made by people surveying the damaged area. Because of these uncertainties, analysis of $M M I$ data typically features wide scatters as shown in Fig. 7. What is important though is to ensure that there is no significant overall bias in the correlation between the simulated and the observed data as is demonstrated clearly in Fig. 7.

\subsection{Comparison with Intensities inferred from records of the Tangshan earthquake}

On the $28^{\text {th }}$ of July, 1976, a very strong earthquake of magnitude Ms $=7.7$ occurred right under Tangshan City in Hebei province. The event caused almost complete destruction of Tangshan city (with epicenter intensity XI) and significant damage in the Beijing area $(M M I=\mathrm{VI}-\mathrm{VIII})$. The Tangshan earthquake has attracted attention by many researchers in the past three decades. It is therefore of interests to conduct a comparison of damage information recorded from the event with findings from 
simulations of the seismological models developed in this study. Historical data obtained in the Tangshan earthquake have been collected from a number of studies (State Seismological Bureau (SSB), 1981; Chen et al., 1988; Gao, 1990; Dan et al., 1993; Sun et al., 1998). They can be in the form of response spectral values, peak ground acceleration or velocity and also MMI. In the comparative analysis shown below, all the data have been converted to MMI for consistency. Similarly, ground motions simulated by the seismological model have also been converted into $M M I$ units based on the methodology described in the previous section.

In Fig. 8, a number of $M M I$ attenuation relationships obtained from seismological modelling are plotted and superposed onto empirical data from historical events. The significant differences between predictions from the individual attenuation relationships in the distance range of $\mathrm{R}>50 \mathrm{~km}$ are due to the different values of $Q$ being adopted (i.e. $Q$ values of 100, 350 and 600). The importance of resolving differences in the attenuation characteristics between the sub-regions is once again demonstrated. Clearly, the attenuation relationship associated with the adopted $Q$ value of 100 is shown to best match with data obtained from other sources based on field observations (as shown by the symbols in Fig. 8). The remarkably good match within the distance range of $100-200 \mathrm{~km}$ is of particular interests. Similar $Q$ value was shown by the contour map of Jin and Aki (1988). The vicinity of the Tangshan area is shown to be characterised by a much lower $Q$ value than the general conditions within SKP.

In contrast, attenuation relationships that are aligned with the conditions of $\operatorname{SCF}(Q=$ $350)$ and that of $\mathrm{YZP}(Q=600)$ are in huge discrepancies with field observations. The converted discrepancies, in terms of the $P G V$ or response spectral velocity values, would have resulted in an over-estimation in the order of $90 \%$ and $140 \%$ respectively.

\subsection{Comparison with existing attenuation model developed for Eastern China}


Wang et al. (2000) has developed two sets of attenuation relationships: one for Eastern China and the other for Western China. The model for Eastern China was selected for comparison with those derived from stochastic simulations of the seismological models developed in this study. Attenuation relationships expressed in terms of effective peak acceleration $(E P A)$ and effective peak velocity $(E P V)$ have been derived by Wang et al. (2000) based on a hybrid empirical procedure (which could make good use of the abundant macroseismic Intensity data recorded in China). By comparing the Intensity attenuation models developed for China and California, the attenuation relationships of $E P A$ and $E P V$ for China can be derived by scaling the selected model previously derived for California.

The effective peak velocity parameter, $E P V$, is chosen herein as the parameter for comparison, as it provides a more robust attenuation characteristics than acceleration based parameters. (It is noteworthy that $E P V$ is not to be confused with $P G V$ given that $E P V$ values used in the foregoing analysis were calculated by dividing the maximum response spectral velocity by a factor of 2.5). The validity of the seismological models developed in this study is further supported by the broad agreement with the empirical model of Wang et al. (2000) as demonstrated by the comparisons shown in Fig. 9 for $\mathrm{M}=5,6,7$ and 8 .

\section{Discussion}

\subsection{Modelling intra-regional differences}

Seismic response spectra are usually developed based on rigorous micro-zonation modelling, considering modifications by the soil sediments overlying bedrock. These micro-zonation modelling are often carried out without paying adequate attention to the modelling of intra-regional variation in the geological properties of bedrock. However, variations in bedrock conditions are deemed to have been taken into account by empirical studies of earthquake accelerograms recorded on the ground 
surface. Most of the existing empirical attenuation models are based on the broad geographical sub-divisions (Sadigh et al., 1997; Abrahamson and Silva, 1997; Toro et al., 1997; Atkinson and Boore, 1997; Dahle et al., 1990; Ambraseys et al., 1996). Ground motions predicted by these models differ by some $50-100 \%$ for similar earthquake scenarios and tectonic classifications (as reviewed in Hutchinson et al., 2003). Although significance of inter-regional variability in the bedrock condition is evident, the enlisted empirical relationships would not necessarily model accurately variability in geological conditions (i.e. intra-regional variability) if a diversity of conditions exists within the accelerogram database. Moreover, the paucity of strong motion earthquake acceleorgrams in stable continental shield regions and regions of low to moderate seismicity implies that even less is known of both inter-regional and intra-regional variability in the bedrock conditions and their influences upon the developed seismic hazard models. The hybrid seismological modelling approach illustrated in this paper provides a means of modelling such variability by drawing upon important information that are embedded in Intensity data of historical events.

Attenuation relationships of the three sub-regions of Eastern China have been developed based on the seismological models proposed in this study. The predicted ratios of the attenuation relationships normalised with respect to that of SKP are shown in Fig. 10 for $M=5,6,7$ and 8. It is observed that the possible intra-regional differences are significant, in particular for far-field earthquakes exceeding $100 \mathrm{~km}$ where anelastic attenuation becomes important. The ratio attains a value of two (i.e. $100 \%$ difference) when $\mathrm{R}$ is greater than $230 \mathrm{~km}$ for YZP and $450 \mathrm{~km}$ for SCF.

As mentioned earlier, far-field large magnitude earthquake events are typified by lowfrequency (long period) seismic waves. Such induced ground shaking can be disproportionately destructive due to its high displacement-velocity shaking characteristics. Distant earthquakes represent potentially significant seismic hazards especially in low to moderate seismic regions where seismic activities are governed by identifiable distant sources as opposed to (nearby) background sources. 
Two scenario earthquake events have been selected to study the differences in response spectrum modelling for near-field and far-field earthquake events for the three selected regions of eastern China. As shown in Fig. 11(a), response spectra simulated for the near-field earthquake event of $M=5.8$ and $R=65 \mathrm{~km}$, using models developed for the three sub-regions show little differences in the period range of engineering interests $(0.1-2.0 \mathrm{~s})$. On the contrary, as shown in Fig. 11(b), response spectra simulated for the far-field earthquake event of $M=7.6$ and $R=330 \mathrm{~km}$, see significant differences in the predicted response spectral velocity between the subregions. The SKP region characterized by lower $Q$-factor produces the lowest response spectral velocity. Some $100 \%$ difference is shown with predictions for the SKP and YZP regions. Such significant intra-regional differences with the response spectral velocity simulated for the same earthquake scenario (M-R combination) have not been suggested in a previous study of Eastern China.

\subsection{Modelling path differences}

Seismic waves propagate to a greater depth if the source-site distance is larger and, in almost all cases, the crustal quality would improve with increasing depth. Hence, a higher $Q$ value should be expected for greater depth and in turn, for larger source-site distance. Thus, strictly speaking, the $Q$ factor would differ between individual earthquake events within the same region. In Hong Kong, for example, modelling path variability can be achieved by employing the $Q$ contour map developed by Mak et al. (2004). An example of distance-dependent $Q$ relationship for Southeastern Australia was given in Allen (2004), which is basically a bi-linear relationship between $Q$ and source-site distance R.

A similar approach has been attempted for modelling the MMI attenuation relationship in this study. The linear $Q$-R relationship starts at 25 for $\mathrm{R}=50 \mathrm{~km}$ and increases up to a value of 250 for $\mathrm{R}=500 \mathrm{~km}$. The extremely low value for the near source region is based on a recently study by Matsunami et al. (2003), who found a $Q$ 
value of 29 , for the upper crust in the vicinity of the epicentre of the 1976 Tangshan earthquake.

It can be seen in Fig. 8 that the $M M I$ attenuation relationship resulting from the proposed distance-dependent $Q$ matches with historical records even better than the attenuation relationship based on a single $Q$ value of 100 . Nonetheless, both the distance-dependent $Q$ formula and the resulting comparison require further research before any firm recommendations can be made.

\section{Conclusions}

1. Stochastic simulations of the seismological model has been developed as a viable means of modelling seismic ground motion parameters (and response spectra) for regions of low to moderate seismicity lacking ground motion records. Realistic simulations are possible when representative regional and local parameters are modelled.

2. Shear wave velocity $(S W V)$ profiles of the three selected regions in Eastern China have been constructed based on published experimental data and results of seismological refraction surveys as reported in the global database CRUST2.0. Strong correlation has been observed between the $S W V$ profiles and the crustal quality $(Q)$ factor.

3. The developed seismological models have been applied for the three selected subregions within Eastern China. Significant differences in the predicted ground motion parameters due to regional differences in the geological conditions have been observed.

4. The developed seismological models have been rigorously calibrated and verified for each sub-region, using historical Intensity data. The site (soil) effects inherent in the database have been quantified and further employed for calibrating the $Q$-value for each sub-region. 
5. Remarkable agreements have been observed between the proposed seismological model and field data from 1976 Tangshan earthquake when the appropriate seismological parameters have been incorporated into the simulations.

6. Distance-dependent $Q$-factor could be a possible improvement over a constant $Q$ factor for seismic hazard study of Eastern China.

7. Based on the findings of this study, ground motion parameters could be refined, especially for distant (far-field) earthquakes.

\section{Acknowledgements}

This work was supported by the Small Project Funding from the University Research Committee (URC) of The University of Hong Kong (Project No. 200707176078), whose support is gratefully acknowledged. 


\section{Appendix A}

(a) Sino-Korean Paraplatform (SKP)

\begin{tabular}{|c|c|c|c|c|c|c|c|c|c|}
\hline No. & Year & Month & $\mathbf{N}$ & $\mathbf{E}$ & $\mathbf{M}$ & $M M I$ & $\begin{array}{c}\mathbf{R a} \\
(\mathbf{k m})\end{array}$ & $\begin{array}{c}\mathbf{R b} \\
(\mathbf{k m})\end{array}$ & $\begin{array}{c}\mathbf{R v} \\
(\mathbf{k m})\end{array}$ \\
\hline 1 & 777 & - & 37.8 & 115.2 & 6 & 8 & 22 & 10 & 15 \\
\hline 2 & 1022 & 4 & 39.8 & 113.1 & 6.5 & 8 & 36 & 11 & 20 \\
\hline 3 & 1038 & 1 & 38.4 & 112.9 & 7.25 & 10 & 15 & 13 & 14 \\
\hline 4 & 1068 & 8 & 38.5 & 116.1 & 6 & 8 & 89 & 50 & 67 \\
\hline 5 & 1304 & 2 & 36.1 & 111.5 & 5.5 & 7 & 14 & 7 & 10 \\
\hline 6 & 1502 & 1 & 34.8 & 110.1 & 5 & 6 & 64 & 29 & 43 \\
\hline 7 & 1502 & 10 & 35.7 & 115.3 & 6.5 & 8 & 46 & 32 & 39 \\
\hline \multirow[t]{5}{*}{8} & 1548 & 9 & 38 & 121 & 7 & 9 & 49 & 21 & 32 \\
\hline & & & & & & 8 & 98 & 49 & 69 \\
\hline & & & & & & 7 & 209 & 106 & 149 \\
\hline & & & & & & 6 & 319 & 188 & 245 \\
\hline & & & & & & 5 & 532 & 352 & 433 \\
\hline \multirow[t]{6}{*}{9} & 1556 & 2 & 34.5 & 109.8 & 8 & 11 & 24 & 15 & 19 \\
\hline & & & & & & 10 & 81 & 26 & 46 \\
\hline & & & & & & 9 & 120 & 39 & 68 \\
\hline & & & & & & 8 & 171 & 60 & 101 \\
\hline & & & & & & 7 & 279 & 153 & 207 \\
\hline & & & & & & 6 & 405 & 252 & 320 \\
\hline 10 & 1587 & 4 & 35.3 & 113.5 & 6 & 7 & 53 & 29 & 39 \\
\hline 11 & 1618 & 5 & 37 & 111.9 & 6.5 & 8 & 25 & 13 & 18 \\
\hline 12 & 1618 & 11 & 39.8 & 114.5 & 6.5 & 8 & 36 & 22 & 28 \\
\hline 13 & 1622 & 3 & 35.5 & 116 & 6 & 8 & 32 & 24 & 28 \\
\hline 14 & 1624 & 4 & 39.8 & 118.8 & 6.25 & 8 & 47 & 23 & 33 \\
\hline 15 & 1626 & 6 & 39.4 & 114.2 & 7 & 9 & 55 & 40 & 47 \\
\hline 16 & 1642 & 6 & 35.1 & 111.1 & 6 & 8 & 65 & 40 & 51 \\
\hline 17 & 1654 & 9 & 36.1 & 115.6 & 5.5 & 7 & 22 & 16 & 19 \\
\hline 18 & 1665 & 4 & 39.9 & 116.6 & 6.5 & 8 & 36 & 24 & 29 \\
\hline \multirow[t]{7}{*}{19} & 1668 & 7 & 34.8 & 118.5 & 8.5 & 12 & 45 & 25 & 34 \\
\hline & & & & & & 11 & 95 & 55 & 72 \\
\hline & & & & & & 10 & 165 & 95 & 125 \\
\hline & & & & & & 9 & 265 & 170 & 212 \\
\hline & & & & & & 8 & 440 & 290 & 357 \\
\hline & & & & & & 7 & 530 & 420 & 472 \\
\hline & & & & & & 6 & 1060 & 800 & 921 \\
\hline 20 & 1683 & 11 & 38.7 & 112.7 & 7 & 9 & 38 & 31 & 34 \\
\hline 21 & 1695 & 5 & 36 & 111.5 & 8 & 10 & 50 & 39 & 44 \\
\hline 22 & 1720 & 7 & 40.4 & 115.5 & 6.75 & 9 & 124 & 68 & 92 \\
\hline 23 & 1815 & 10 & 34.8 & 111.2 & 6.75 & 9 & 33 & 17 & 24 \\
\hline
\end{tabular}




\begin{tabular}{|c|c|c|c|c|c|c|c|c|c|}
\hline 24 & 1829 & 11 & 36.6 & 118.5 & 6 & 8 & 48 & 28 & 37 \\
\hline \multirow[t]{5}{*}{25} & 1830 & 6 & 36.4 & 114.2 & 7.5 & 10 & 15 & 6 & 10 \\
\hline & & & & & & 9 & 30 & 18 & 23 \\
\hline & & & & & & 8 & 50 & 31 & 39 \\
\hline & & & & & & 7 & 98 & 88 & 93 \\
\hline & & & & & & 6 & 178 & 166 & 172 \\
\hline 26 & 1882 & 12 & 38.1 & 115.5 & 6 & 8 & 19 & 14 & 17 \\
\hline 27 & 1891 & 4 & 37.1 & 111.9 & 5.75 & 7 & 25 & 18 & 21 \\
\hline \multirow[t]{2}{*}{28} & 1929 & 1 & 40.7 & 111.3 & 6 & 5 & 30 & 20 & 24 \\
\hline & & & & & & 4 & 49 & 33 & 40 \\
\hline \multirow[t]{5}{*}{29} & 1937 & 8 & 35.4 & 115.1 & 7 & 9 & 7 & 5 & 6 \\
\hline & & & & & & 8 & 16 & 12 & 14 \\
\hline & & & & & & 7 & 52 & 32 & 41 \\
\hline & & & & & & 6 & 240 & 157 & 194 \\
\hline & & & & & & 5 & 489 & 443 & 466 \\
\hline \multirow[t]{4}{*}{30} & 1939 & 1 & 37.1 & 121.6 & 5.5 & 7 & 4.1 & 1.6 & 2.6 \\
\hline & & & & & & 6 & 13 & 6 & 9 \\
\hline & & & & & & 5 & 25 & 13 & 18 \\
\hline & & & & & & 4 & 57 & 37 & 46 \\
\hline 31 & 1940 & 8 & 40.2 & 122 & 5.75 & 8 & 19 & 11 & 15 \\
\hline \multirow[t]{2}{*}{32} & 1945 & 9 & 39.5 & 119 & 6.25 & 8 & 13 & 9 & 11 \\
\hline & & & & & & 7 & 27 & 24 & 26 \\
\hline \multirow[t]{3}{*}{33} & 1952 & 10 & 39 & 112.7 & 5.5 & 8 & 7 & 5 & 6 \\
\hline & & & & & & 7 & 16 & 12 & 14 \\
\hline & & & & & & 6 & 33 & 25 & 29 \\
\hline \multirow[t]{2}{*}{34} & 1956 & 8 & 37.8 & 114 & 5 & 6 & 1.2 & 0.4 & 0.7 \\
\hline & & & & & & 5 & 5.1 & 3.0 & 3.9 \\
\hline \multirow[t]{3}{*}{35} & 1957 & 1 & 40.5 & 115.5 & 5 & 5 & 17 & 11 & 14 \\
\hline & & & & & & 4 & 42 & 32 & 37 \\
\hline & & & & & & 3 & 93 & 70 & 81 \\
\hline \multirow[t]{4}{*}{36} & 1959 & 8 & 35.6 & 110.9 & 5.6 & 7 & 21 & 9 & 14 \\
\hline & & & & & & 6 & 31 & 17 & 23 \\
\hline & & & & & & 5 & 63 & 42 & 51 \\
\hline & & & & & & 4 & 143 & 85 & 110 \\
\hline \multirow[t]{3}{*}{37} & 1965 & 1 & 35 & 111.6 & 5.5 & 6 & 38 & 30 & 34 \\
\hline & & & & & & 5 & 126 & 120 & 123 \\
\hline & & & & & & 4 & 226 & 172 & 197 \\
\hline \multirow[t]{3}{*}{38} & 1966 & 3 & 37.5 & 115 & 5.5 & 7 & 5.6 & 2.5 & 3.7 \\
\hline & & & & & & 6 & 21 & 9 & 14 \\
\hline & & & & & & 5 & 56 & 32 & 42 \\
\hline \multirow[t]{4}{*}{39} & 1966 & 3 & 37.4 & 114.9 & 6.8 & 8 & 24 & 16 & 19 \\
\hline & & & & & & 7 & 42 & 34 & 37 \\
\hline & & & & & & 6 & 101 & 63 & 80 \\
\hline & & & & & & 5 & 291 & 272 & 281 \\
\hline
\end{tabular}




\begin{tabular}{|c|c|c|c|c|c|c|c|c|c|}
\hline & & & & & & 4 & 499 & 474 & 486 \\
\hline \multirow[t]{4}{*}{40} & 1966 & 3 & 37.5 & 115.1 & 7.2 & 10 & 5.5 & 2.7 & 3.9 \\
\hline & & & & & & 9 & 13 & 9 & 11 \\
\hline & & & & & & 8 & 35 & 23 & 28 \\
\hline & & & & & & 7 & 51 & 44 & 47 \\
\hline \multirow[t]{2}{*}{41} & 1966 & 3 & 37.7 & 115.3 & 6.2 & 7 & 8 & 6 & 7 \\
\hline & & & & & & 6 & 32 & 24 & 28 \\
\hline \multirow[t]{3}{*}{42} & 1966 & 3 & 37.4 & 115 & 6 & 8 & 2.1 & 1.6 & 1.8 \\
\hline & & & & & & 7 & 7 & 5 & 6 \\
\hline & & & & & & 6 & 20 & 13 & 16 \\
\hline \multirow[t]{3}{*}{43} & 1966 & 3 & 37.5 & 115 & 5.2 & 7 & 6.2 & 3.0 & 4.3 \\
\hline & & & & & & 6 & 22 & 9 & 14 \\
\hline & & & & & & 5 & 58 & 32 & 43 \\
\hline \multirow[t]{3}{*}{44} & 1967 & 3 & 38.5 & 116.5 & 6.3 & 7 & 7.5 & 3.0 & 4.7 \\
\hline & & & & & & 6 & 80 & 50 & 63 \\
\hline & & & & & & 5 & 138 & 87 & 110 \\
\hline \multirow[t]{3}{*}{45} & 1967 & 7 & 40.7 & 115.8 & 5.4 & 6 & 14 & 9 & 11 \\
\hline & & & & & & 5 & 37 & 28 & 32 \\
\hline & & & & & & 4 & 72 & 56 & 63 \\
\hline \multirow{3}{*}{46} & 1967 & 12 & 37.7 & 115.2 & 5.7 & 7 & 8 & 5 & 6 \\
\hline & & & & & & 6 & 15 & 13 & 14 \\
\hline & & & & & & 5 & 56 & 33 & 43 \\
\hline \multirow[t]{2}{*}{47} & 1967 & 12 & 36.5 & 111.2 & 5.4 & 6 & 36 & 35 & 35 \\
\hline & & & & & & 5 & 100 & 79 & 89 \\
\hline \multirow[t]{3}{*}{48} & 1969 & 7 & 38.2 & 119.4 & 7.4 & 7 & 88 & 85 & 86 \\
\hline & & & & & & 6 & 165 & 155 & 160 \\
\hline & & & & & & 5 & 300 & 295 & 298 \\
\hline \multirow[t]{2}{*}{49} & 1973 & 12 & 38.4 & 116.8 & 5.1 & 6 & 13 & 10 & 11 \\
\hline & & & & & & 5 & 54 & 41 & 47 \\
\hline \multirow[t]{3}{*}{50} & 1976 & 4 & 40.2 & 112.2 & 6.3 & 7 & 29 & 9 & 16 \\
\hline & & & & & & 6 & 59 & 20 & 34 \\
\hline & & & & & & 5 & 131 & 79 & 101 \\
\hline \multirow[t]{5}{*}{51} & 1976 & 7 & 39.4 & 118 & 7.8 & 11 & 5.7 & 2.9 & 4.0 \\
\hline & & & & & & 10 & 13 & 9 & 11 \\
\hline & & & & & & 9 & 47 & 23 & 33 \\
\hline & & & & & & 8 & 67 & 57 & 62 \\
\hline & & & & & & 7 & 136 & 93 & 112 \\
\hline \multirow[t]{2}{*}{52} & 1976 & 9 & 40 & 106.5 & 6.2 & 7 & 44 & 24 & 33 \\
\hline & & & & & & 6 & 73 & 58 & 65 \\
\hline \multirow[t]{3}{*}{53} & 1981 & 8 & 40.5 & 113.4 & 5.8 & 7 & 11 & 6 & 8 \\
\hline & & & & & & 6 & 18 & 16 & 17 \\
\hline & & & & & & 5 & 56 & 41 & 48 \\
\hline
\end{tabular}




\begin{tabular}{|c|c|c|c|c|c|c|c|c|c|}
\hline No. & Year & Month & $\mathbf{N}$ & $\mathbf{E}$ & $\mathbf{M}$ & MMI & $\begin{array}{c}\mathbf{R a} \\
(\mathbf{k m})\end{array}$ & $\begin{array}{c}\mathbf{R b} \\
(\mathbf{k m})\end{array}$ & $\begin{array}{c}\mathbf{R v} \\
(\mathbf{k m})\end{array}$ \\
\hline 1 & 788 & 3 & 32.5 & 109.4 & 6.5 & 8 & 34 & 21 & 27 \\
\hline 2 & 1361 & - & 28.8 & 115.3 & 5 & 6 & 42 & 18 & 27 \\
\hline 3 & 1487 & 8 & 34.4 & 108.9 & 6.25 & 8 & 13 & 13 & 13 \\
\hline 4 & 1522 & 1 & 34.2 & 114.1 & 5.75 & 7 & 26 & 16 & 20 \\
\hline 5 & 1524 & 2 & 34 & 114 & 5.75 & 7 & 21 & 12 & 16 \\
\hline 6 & 1585 & 3 & 31.2 & 117.7 & 5.5 & 7 & 63 & 25 & 40 \\
\hline 7 & 1624 & 2 & 32.4 & 119.5 & 6 & 7 & 113 & 76 & 93 \\
\hline 8 & 1631 & 8 & 29.3 & 111.7 & 6.5 & 8 & 97 & 72 & 84 \\
\hline 9 & 1662 & 10 & 33.2 & 114.8 & 5.5 & 7 & 75 & 63 & 69 \\
\hline 10 & 1820 & 8 & 34.1 & 113.9 & 6 & 8 & 15 & 10 & 12 \\
\hline 11 & 1831 & 9 & 32.8 & 116.8 & 6.25 & 8 & 67 & 53 & 60 \\
\hline 12 & 1913 & 4 & 32.2 & 119.5 & 5.5 & 7 & 32 & 21 & 26 \\
\hline 13 & 1917 & 1 & 31.3 & 116.2 & 6.25 & 8 & 32 & 18 & 24 \\
\hline \multirow[t]{3}{*}{14} & 1932 & 4 & 31.4 & 115 & 6 & 8 & 7.6 & 4.0 & 5.5 \\
\hline & & & & & & 7 & 12 & 8 & 10 \\
\hline & & & & & & 6 & 21 & 12 & 16 \\
\hline \multirow[t]{4}{*}{15} & 1954 & 6 & 31.6 & 116.6 & 5.25 & 6 & 131 & 61 & 90 \\
\hline & & & & & & 5 & 172 & 102 & 133 \\
\hline & & & & & & 4 & 201 & 160 & 179 \\
\hline & & & & & & 3 & 286 & 246 & 265 \\
\hline \multirow[t]{2}{*}{16} & 1959 & 7 & 31.8 & 115.3 & 5 & 6 & 3.4 & 2.3 & 2.8 \\
\hline & & & & & & 5 & 10 & 7 & 8 \\
\hline \multirow[t]{2}{*}{17} & 1961 & 3 & 30.5 & 110 & 5 & 6 & 20 & 14 & 17 \\
\hline & & & & & & 5 & 51 & 39 & 45 \\
\hline \multirow[t]{3}{*}{18} & 1965 & 1 & 35 & 111.6 & 5.5 & 6 & 38 & 30 & 34 \\
\hline & & & & & & 5 & 126 & 120 & 123 \\
\hline & & & & & & 4 & 226 & 172 & 197 \\
\hline \multirow[t]{3}{*}{19} & 1974 & 4 & 31.4 & 119.2 & 5.5 & 7 & 7.8 & 3.9 & 5.5 \\
\hline & & & & & & 6 & 28 & 12 & 18 \\
\hline & & & & & & 5 & 38 & 28 & 33 \\
\hline \multirow[t]{3}{*}{20} & 1979 & 5 & 31.1 & 110.5 & 5.1 & 7 & 6.8 & 3.3 & 4.8 \\
\hline & & & & & & 6 & 14 & 9 & 12 \\
\hline & & & & & & 5 & 25 & 18 & 21 \\
\hline \multirow[t]{5}{*}{21} & 1979 & 7 & 31.5 & 119.3 & 6 & 8 & 3.0 & 2.0 & 2.4 \\
\hline & & & & & & 7 & 16 & 13 & 14 \\
\hline & & & & & & 6 & 32 & 28 & 29 \\
\hline & & & & & & 5 & 223 & 143 & 178 \\
\hline & & & & & & 4 & 263 & 251 & 257 \\
\hline
\end{tabular}




\begin{tabular}{|c|c|c|c|c|c|c|c|c|c|}
\hline No. & Year & Month & $\mathbf{N}$ & $\mathbf{E}$ & $\mathbf{M}$ & MMI & $\begin{array}{c}\mathbf{R a} \\
(\mathbf{k m})\end{array}$ & $\begin{array}{c}\mathbf{R b} \\
(\mathbf{k m})\end{array}$ & $\begin{array}{c}\mathbf{R v} \\
(\mathbf{k m})\end{array}$ \\
\hline \multirow[t]{4}{*}{1} & 1067 & 11 & 23.6 & 116.6 & 6.75 & 9 & 16 & 10 & 13 \\
\hline & & & & & & 8 & 37 & 27 & 32 \\
\hline & & & & & & 7 & 74 & 63 & 68 \\
\hline & & & & & & 6 & 155 & 133 & 144 \\
\hline 2 & 1318 & 6 & 24.2 & 110 & 5 & 4 & 100 & 32 & 57 \\
\hline 3 & 1372 & 5 & 24.2 & 111.1 & 5.25 & 4 & 94 & 64 & 78 \\
\hline \multirow[t]{3}{*}{4} & 1445 & 12 & 24.6 & 117.6 & 6.25 & 8 & 15 & 8 & 11 \\
\hline & & & & & & 7 & 34 & 22 & 27 \\
\hline & & & & & & 6 & 69 & 50 & 59 \\
\hline 5 & 1485 & 10 & 22.6 & 110.2 & 5.25 & 4 & 160 & 34 & 74 \\
\hline 6 & 1502 & 7 & 24 & 110.9 & 5 & 4 & 90 & 32 & 54 \\
\hline 7 & 1507 & 3 & 23 & 110.4 & 5.25 & 4 & 114 & 60 & 83 \\
\hline 8 & 1508 & 11 & 23.6 & 115.8 & 5.25 & 4 & 143 & 69 & 99 \\
\hline 9 & 1509 & 10 & 21.6 & 110.7 & 5 & 5 & 50 & 28 & 37 \\
\hline 10 & 1510 & 1 & 21.6 & 110.7 & 5 & 5 & 50 & 28 & 37 \\
\hline 11 & 1510 & 11 & 24.5 & 109.5 & 5 & 4 & 109 & 36 & 63 \\
\hline 12 & 1519 & 9 & 23.3 & 117.3 & 5 & 4 & 93 & 60 & 75 \\
\hline 13 & 1520 & 7 & 23.9 & 111 & 5 & 4 & 92 & 45 & 64 \\
\hline \multirow[t]{4}{*}{14} & 1556 & 1 & 29.5 & 113.2 & 5.5 & 7 & 31 & 13 & 20 \\
\hline & & & & & & 6 & 71 & 33 & 48 \\
\hline & & & & & & 5 & 125 & 70 & 94 \\
\hline & & & & & & 4 & 194 & 144 & 167 \\
\hline \multirow[t]{4}{*}{15} & 1558 & 6 & 23.4 & 111.5 & 5.5 & 7 & 4 & 2 & 3 \\
\hline & & & & & & 6 & 15 & 8 & 11 \\
\hline & & & & & & 5 & 45 & 26 & 34 \\
\hline & & & & & & 4 & 123 & 66 & 90 \\
\hline \multirow[t]{4}{*}{16} & 1574 & 8 & 26.1 & 119.3 & 5.75 & 7 & 32 & 22 & 27 \\
\hline & & & & & & 6 & 58 & 42 & 49 \\
\hline & & & & & & 5 & 104 & 80 & 91 \\
\hline & & & & & & 4 & 204 & 158 & 180 \\
\hline 17 & 1584 & 7 & 23.3 & 112.5 & 5.25 & 4 & 150 & 84 & 112 \\
\hline 18 & 1599 & 1 & 21.5 & 110.5 & 5.5 & 4 & 180 & 158 & 169 \\
\hline \multirow[t]{4}{*}{19} & 1600 & 9 & 25.5 & 117.2 & 7 & 9 & 18 & 15 & 16 \\
\hline & & & & & & 8 & 45 & 40 & 42 \\
\hline & & & & & & 7 & 94 & 84 & 89 \\
\hline & & & & & & 6 & 165 & 146 & 155 \\
\hline \multirow[t]{4}{*}{20} & 1604 & 12 & 25 & 119.5 & 8 & 10 & 20 & 13 & 16 \\
\hline & & & & & & 9 & 36 & 25 & 30 \\
\hline & & & & & & 8 & 66 & 50 & 57 \\
\hline & & & & & & 7 & 138 & 103 & 119 \\
\hline
\end{tabular}


$\begin{array}{llllll} & 6 & 222 & 190 & 205\end{array}$ $\begin{array}{llllllllll}21 & 1605 & 7 & 20 & 110.5 & 7.5 & 10 & 20 & 11 & 15\end{array}$

$\begin{array}{llll}9 & 45 & 36 & 40\end{array}$

$\begin{array}{llll}8 & 93 & 53 & 70\end{array}$

$\begin{array}{llll}7 & 123 & 86 & 103\end{array}$

$\begin{array}{llllllllll}22 & 1611 & 9 & 21.4 & 111.2 & 6.25 & 7 & 42 & 20 & 29\end{array}$

$\begin{array}{llllllllll}23 & 1631 & 8 & 29.3 & 111.7 & 6.5 & 8 & 33 & 17 & 24\end{array}$

$\begin{array}{llll}7 & 65 & 46 & 55\end{array}$

$\begin{array}{llllllllll}24 & 1639 & 6 & 24.7 & 110.5 & 5 & 4 & 82 & 30 & 50\end{array}$

$\begin{array}{llllllllll}25 & 1641 & 11 & 23.5 & 116.5 & 5.75 & 7 & 16 & 10 & 13\end{array}$

$\begin{array}{llll}6 & 38 & 27 & 32\end{array}$

$\begin{array}{llll}5 & 74 & 65 & 69\end{array}$

$\begin{array}{llllllllll}26 & 1651 & 2 & 26.2 & 116.6 & 5.5 & 7 & 14 & 8 & 11\end{array}$

$\begin{array}{llll}6 & 41 & 26 & 33\end{array}$

$\begin{array}{llll}5 & 103 & 68 & 84\end{array}$

$\begin{array}{llll}4 & 238 & 222 & 230\end{array}$

$\begin{array}{llllllllll}27 & 1664 & 9 & 22 & 112.5 & 5.25 & 5 & 23 & 21 & 22\end{array}$

$\begin{array}{llllllllll}28 & 1665 & 9 & 24.5 & 110.6 & 5 & 4 & 142 & 30 & 65\end{array}$

$\begin{array}{llllllllll}29 & 1686 & 1 & 22.5 & 110.6 & 5.25 & 4 & 158 & 56 & 94\end{array}$

$\begin{array}{llllllllll}30 & 1695 & 2 & 24.8 & 109.2 & 5.5 & 4 & 150 & 107 & 127\end{array}$

$\begin{array}{llllllllll}31 & 1778 & 10 & 22.9 & 110.3 & 5 & 4 & 82 & 42 & 59\end{array}$

$\begin{array}{llllllllll}32 & 1792 & 8 & 23.6 & 120.6 & 7 & 9 & 25 & 8 & 14\end{array}$

$8 \quad 50 \quad 25 \quad 35$

$\begin{array}{llll}7 & 90 & 40 & 60\end{array}$

$\begin{array}{llll}6 & 120 & 60 & 85\end{array}$

$\begin{array}{llllllllll}33 & 1806 & 1 & 25.3 & 115.7 & 6 & 8 & 11 & 7 & 9\end{array}$

$\begin{array}{llll}7 & 22 & 15 & 18\end{array}$

$\begin{array}{llll}6 & 50 & 33 & 41\end{array}$

$5 \quad 103 \quad 72 \quad 86$

$4 \quad 195 \quad 165 \quad 179$

$\begin{array}{llllllllll}34 & 1824 & 8 & 23 & 113.3 & 5 & 5 & 19 & 14 & 16\end{array}$

$\begin{array}{lllllll} & & 4 & 63 & 47 & 54\end{array}$

$\begin{array}{llllllllll}35 & 1860 & 1 & 22.5 & 110.2 & 5.5 & 4 & 174 & 124 & 147\end{array}$

$\begin{array}{llllllllll}36 & 1874 & 7 & 23 & 115.3 & 5 & 6 & 30 & 8 & 15\end{array}$

$\begin{array}{llll}5 & 60 & 30 & 42\end{array}$

$\begin{array}{llllllllll}37 & 1875 & 6 & 24 & 107 & 6 & 4 & 348 & 240 & 289\end{array}$

$\begin{array}{llllllllll}38 & 1890 & 8 & 21.9 & 110.1 & 5.75 & 6 & 59 & 30 & 42\end{array}$

$4 \quad 300 \quad 180 \quad 232$

$\begin{array}{llllllllll}39 & 1890 & 11 & 22.1 & 110.5 & 5 & 4 & 86 & 44 & 62\end{array}$

$\begin{array}{llllllllll}40 & 1895 & 8 & 23.5 & 116.4 & 6 & 8 & 22 & 13 & 17\end{array}$

$\begin{array}{llll}7 & 46 & 35 & 40\end{array}$ 


\begin{tabular}{|c|c|c|c|c|c|c|c|c|c|}
\hline & & & & & & 6 & 88 & 70 & 78 \\
\hline 41 & 1899 & 11 & 23.6 & 109.6 & 5 & 4 & 84 & 32 & 52 \\
\hline 42 & 1905 & 8 & 22.1 & 113.4 & 5.5 & 4 & 228 & 132 & 173 \\
\hline \multirow[t]{3}{*}{43} & 1906 & 3 & 24.5 & 118.5 & 6.3 & 7 & 100 & 50 & 71 \\
\hline & & & & & & 6 & 360 & 200 & 268 \\
\hline & & & & & & 5 & 680 & 410 & 528 \\
\hline 44 & 1911 & 5 & 22.5 & 115 & 6 & 4 & 282 & 192 & 233 \\
\hline \multirow[t]{5}{*}{45} & 1918 & 2 & 23.5 & 117.2 & 7.3 & 10 & 19 & 16 & 17 \\
\hline & & & & & & 9 & 35 & 30 & 32 \\
\hline & & & & & & 8 & 83 & 60 & 71 \\
\hline & & & & & & 7 & 144 & 126 & 135 \\
\hline & & & & & & 6 & 302 & 207 & 250 \\
\hline \multirow[t]{5}{*}{46} & 1936 & 4 & 22.6 & 109.5 & 6.75 & 9 & 10 & 6 & 8 \\
\hline & & & & & & 8 & 21 & 14 & 17 \\
\hline & & & & & & 7 & 54 & 31 & 41 \\
\hline & & & & & & 6 & 120 & 64 & 88 \\
\hline & & & & & & 5 & 268 & 146 & 198 \\
\hline \multirow[t]{4}{*}{47} & 1941 & 9 & 25.1 & 115.6 & 5.75 & 7 & 10 & 7 & 8 \\
\hline & & & & & & 6 & 35 & 30 & 32 \\
\hline & & & & & & 5 & 87 & 80 & 83 \\
\hline & & & & & & 4 & 200 & 198 & 199 \\
\hline \multirow[t]{4}{*}{48} & 1958 & 9 & 22.6 & 109.5 & 5.75 & 7 & 5 & 3 & 4 \\
\hline & & & & & & 6 & 16 & 11 & 13 \\
\hline & & & & & & 5 & 45 & 34 & 39 \\
\hline & & & & & & 4 & 120 & 96 & 107 \\
\hline \multirow[t]{3}{*}{49} & 1960 & 11 & 24.3 & 106 & 5 & 6 & 18 & 8 & 12 \\
\hline & & & & & & 5 & 79 & 20 & 40 \\
\hline & & & & & & 4 & 94 & 39 & 61 \\
\hline \multirow[t]{6}{*}{50} & 1962 & 3 & 23.7 & 114.7 & 6.1 & 8 & 8 & 6 & 7 \\
\hline & & & & & & 7 & 20 & 8 & 13 \\
\hline & & & & & & 6 & 84 & 44 & 61 \\
\hline & & & & & & 5 & 269 & 161 & 208 \\
\hline & & & & & & 7 & 28 & 11 & 18 \\
\hline & & & & & & 6 & 50 & 27 & 37 \\
\hline \multirow[t]{3}{*}{51} & 1962 & 4 & 24.3 & 106 & 5 & 6 & 15 & 6 & 9 \\
\hline & & & & & & 5 & 44 & 20 & 30 \\
\hline & & & & & & 4 & 60 & 30 & 42 \\
\hline \multirow[t]{3}{*}{52} & 1962 & 4 & 23.9 & 114.5 & 5 & 6 & 3 & 2 & 2 \\
\hline & & & & & & 5 & 21 & 16 & 18 \\
\hline & & & & & & 4 & 70 & 58 & 64 \\
\hline \multirow[t]{3}{*}{53} & 1964 & 9 & 23.7 & 114.7 & 5.1 & 6 & 10 & 5 & 7 \\
\hline & & & & & & 5 & 41 & 25 & 32 \\
\hline & & & & & & 4 & 109 & 74 & 90 \\
\hline 54 & 1968 & 4 & 24.9 & 117.5 & 5.2 & 6 & 16 & 8 & 11 \\
\hline
\end{tabular}




\begin{tabular}{cccccccccc}
55 & 1969 & 7 & 21.7 & 111.8 & 6.4 & 8 & 13 & 5 & 8 \\
& & & & & & 7 & 28 & 11 & 18 \\
& & & & & & 6 & 50 & 27 & 37 \\
56 & 1977 & 10 & 23.4 & 107.6 & 5 & 6 & 11 & 6 & 8 \\
& & & & & & 5 & 40 & 21 & 29 \\
& & & & & & 4 & 128 & 68 & 93 \\
57 & 1982 & 2 & 24.7 & 114.8 & 5 & 6 & 14 & 6 & 9 \\
& & & & & & 5 & 65 & 30 & 44 \\
\hline
\end{tabular}




\section{References}

Abercrombie, R.E., 1997. Near-surface attenuation and site effects from comparison of surface and deep borehole recordings. Bulletin of the Seismological Society of America 87 (3), 731-744.

Abrahamson, N.A, Silva, W.J., 1997. Empirical response spectral attenuation relations for shallow crustal earthquakes. Seismological Research Letters 68 (1), 94-127.

Allen, T.I., 2004. Spectral Attenuation and Earthquake Source Parameters from Recorded Ground Motion: Implications for Earthquake Hazard and the Crustal Stress Field of Southeastern Australia. School of Geosciences, Monash University, Melbourne, PhD thesis.

Ambraseys, N.N., Simpson, K.A., Bommer, J.J., 1996. Prediction of horizontal response spectra in Europe. Earthquake Engineering and Structural Dynamics 25, 371-400.

Atkinson, G.M., 1993. Earthquake source spectra in Eastern North America. Bulletin of the Seismological Society of America 83 (6), 1778-1798.

Atkinson, G.M, Boore, D.M., 1995. Ground-motion relations for eastern North America. Bulletin of the Seismological Society of America 85 (1), 17-30.

Atkinson, G.M., Boore, D.M., 1997. Some comparisons between recent ground motion relations. Seismological Research Letters 68 (1), 24-40. 
Atkinson, G.M., Boore, D.M., 1998. Evaluation of models for earthquake source spectra in Eastern North America. Bulletin of the Seismological Society of America 88 (4), 917-937.

Atkinson, G.M., Mereu, R.F., 1992. The shape of ground motion attenuation curves in southeastern Canada. Bulletin of the Seismological Society of America 82 (5), 2014-2031.

Atkinson, G.M., Silva, W., 1997. An empirical study of earthquake source spectra for California earthquakes. Bulletin of the Seismological Society of America 87 (1), 97-113.

Balendra, T., Lam, N.T.K., Wilson, J.L., Kong, K.H., 2002. Analysis of long-distance earthquake tremors and base shear demand for buildings in Singapore. Engineering Structures 24, 99-108.

Boore, D.M., 1983. Stochastic simulation of high-frequency ground motions based on seismological models of the radiated spectra. Bulletin of the Seismological Society of America 73 (6A), 1865-1894.

Boore, D.M., Joyner, W.B., 1997. Site amplification for generic rock sites. Bulletin of the Seismological Society of America 87 (2), 327-341.

Brune, J.N., 1970. Tectonic stress and the spectra of seismic shear waves from earthquakes. Journal of Geophysical Research 75, 4997-5009.

Chandler, A.M., Lam, N.T.K., 2004. An attenuation model for distant earthquakes. Earthquake Engineering and Structural Dynamics 33 (2), 183-210. 
Chandler, A.M., Lam N.T.K., Tsang H.H., 2005a. Shear wave velocity modelling in crustal rock for seismic hazard analysis. Soil Dynamics and Earthquake Engineering 25 (2), 167-185.

Chandler, A.M., Lam N.T.K., Tsang H.H., Sheikh, M.N., 2005b. Estimation of nearsurface attenuation in bedrock for analysis of intraplate seismic hazard. Journal of Seismology and Earthquake Engineering 7 (3), 159 - 173.

Chandler, A.M., Lam, N.T.K., Tsang, H.H., 2006a. Near-surface attenuation modelling based on rock shear-wave velocity profile. Soil Dynamics and Earthquake Engineering 26 (11), 1004-1014.

Chandler, A.M., Lam, N.T.K., Tsang, H.H., 2006b. Regional and local factors in attenuation modelling: Hong Kong case study. Journal of Asian Earth Sciences 27 (6), 892-906.

Chen, Y., Tsoi, K., Chen, F. Gao, Z., Zou, Q., Chen, Z., 1988. The Great Tangshan Earthquake of 1976: An Anatomy of Disaster. Pergamon Press, Oxford, England, U.K.

Dahle A, Bungum H, Kvamme L.B., 1990. Attenuation models inferred from intraplate earthquake recordings. Earthquake Engineering and Structural Dynamics 19, 1125-41.

Dan, K., Ishii, T., Ebihara, M., 1993. Estimation of strong ground motions in meizoseismal region of the 1976 Tangshan, China, earthquake. Bulletin of the Seismological Society of America 83 (6), 1756-1777. 
Deng, Q., 1995. The research of active tectonics and paleoearthquake in China. China National Report on Seismology and Physics of the Earth's Interior for the XXI-th General Assembly of IUGG, Chinese National Committee for the International Union of Geodesy and Geophysics, pp. 96-122.

Feng, R., Zhu, J., Ding, Y., Chen, G., He, Z., Yang, S., Zhou, H., Sun, K., 1981. Crustal structure in China from surface waves. Acta Seismological Sinica 3 (4), 336-350.

Gao, M.T. 2003. New national seismic zoning map of China. Acta Seismologica Sinica 16 (6), 639-645.

Gao, W.X. (Ed.) 1990. China Earthquake Yearbook. Seismological Press, Beijing, China, in Chinese.

Gu, G.X. (Ed.) 1989. Catalogue of Chinese Earthquake (1831 B.C. - 1969 A.D.). Science Press, Beijing, China.

Hu, J., Zhuang, Z., Teng, J., 1992. Mid-long period digital surface-wave data and the crustal structure of south-east China. Acta Geophysica Sinica 35 (5), 584-593, in Chinese.

Hutchinson G.L, Lam N.T.K, Wilson J.L., 2003. Determination of earthquake loading and seismic performance in intraplate regions. Progress in Structural Engineering and Materials 5 (3), 181-194.

Jin, A., Aki, K., 1988. Spatial and temporal correlation between coda Q and seismicity in China. Bulletin of the Seismological Society of America 78 (2), 741 769. 
Lam, N.T.K., Wilson, J.L., Hutchinson, G.L., 2000. Generation of synthetic earthquake accelerograms using seismological modelling: a review. Journal of Earthquake Engineering 4 (3), 321-354.

Lam, N.T.K., Chandler, A.M., Wilson, J.L., Hutchinson, G.L., 2002. Response spectrum predictions for potential near-field and far-field earthquakes affecting Hong Kong: rock sites. Soil Dynamics and Earthquake Engineering 22 (1), 47-72.

Lam, N.T.K., Sinadinovski, C., Koo, R., Wilson, J.L., 2003. Peak ground velocity modelling for Australian intraplate earthquakes. Journal of Seismology and Earthquake Engineering 5 (2), 1-12.

Lam, N.T.K., Venkatesan, S., Wilson, J.L., Asten, M.W., Roberts, J., Chandler, A.M. \& Tsang, H.H., 2006. Generic approach for modelling earthquake hazard. Advances in Structural Engineering 9 (1), 67-82.

Laske, G., Masters, G. and Reif, C., 2000. CRUST2.0: A New Global Crustal Model. Institute of Geophysics and Planetary Physics, The University of California, San Diego. Website: http://mahi.ucsd.edu/Gabi/rem.dir/crust/crust2.html.

Lei, Q., Meng, B., Niu, X., Lu, Z., 1999. Geologic interpretation of seismic tomographic image $3 \mathrm{~km}$ depth in the northeast edge of Sino-Korean Platform. Seismological Research of Northeast China 15 (1), 37-45, in Chinese.

Li, S., Mooney, W.D., 1998. Crustal structure of China from deep seismic sounding profiles. Tectonophysics 288, 105-113. 
Mak, S., Chan, L. S., Chandler, A. M., Koo R. C. H., 2004. Coda Q estimates in the Hong Kong region, Journal of Asian Earth Sciences 24, 127-136.

Matsunami, K., Zhang, W., Irikura, K., Xie, L., 2003. Estimation of seismic site response in the Tangshan area, China, using deep underground records. Bulletin of the Seismological Society of America 93 (3), 1065-1078.

Newmark, N.M., Rosenblueth, E., 1971. Fundamentals of Earthquake Engineering. Prentice-Hall, Englewoodcliffs, NJ.

Qin, C.,Papadimitriou, E.E., Papazachos, B.C., Karakaisis, G.F., 2001. Timedependent seismicity in China. Journal of Asian Earth Sciences 19, 97-128.

Sadigh K, Chang C.Y., Egan J.A., Makdisi F., Youngs R.R., 1997. Attenuation relationships for shallow crustal earthquakes based on Californian strong motion data. Seismological Research Letters 68 (1), 180-189.

Sheng, Q., Yue, Z.Q., Lee, C.F., Tham, L.G. and Zhou, H., 2002. Estimating the excavation disturbed zone in the permanent shiplock slopes of the Three Gorges Project, China. International Journal of Rock Mechanics and Mining Sciences 39, $165-184$.

Song, S.Y., Zhou, X.S, Zhang, X.K., Qiu, S.Y., Gong, Y., Song, J.L., 1998. Judgement and interpretation of S-wave data on the Beijing-Fengzhen DSS profile. Acta Seismological Sinica 11 (1), 71-80.

State Seismological Bureau, 1981. Tangshan di zhen kao cha yu yan jiu (pin yin). Seismological Press, Beijing, China, in Chinese. 
Sun, R., Liu F., 1995. Crust structure and strong earthquake in Beijing, Tianjing, Tangshan area: I. P wave velocity structure. Acta Geophysica Sinica 38 (5), 599607, in Chinese.

Sun, R., Vaccari, F., Marrara, F., Panza, G.F., 1998. The main features of the local geological conditions can explain the macroseismic Intensity caused in XijiLangfu (Beijing) by the M-s = 7.7 Tangshan 1976 earthquake. Pure and Applied Geophysics 152 (3), 507-521.

Sun, R., Vaccari, F., Panza, G.F., 2000. SH-wave modelling of influence of local geological condition on strong ground motion. Chinese Journal of Geophysics 43 (1), 81-90, in Chinese.

Toro G.R., Abrahamson N.A, Schneider J.F., 1997. Model of strong ground motion from earthquakes in Central and Eastern North America: best estimates and uncertainties. Seismological Research Letters 68 (1), 41-57.

Wang, C., Ding, Z., Song, J., Wu, Q., Zheng, J., Zhang, X., 1997. Shear wave velocity structure in Dabieshan orogenic belt. Acta Geophysica Sinica 40 (3), 337-346.

Wang, S., Yu, Y., Gao, A., Yan, X., 2000. Development of attenuation relations for ground motion in China. Earthquake Research in China 16 (2), 99-106, in Chinese.

Xie, L., Zhang, M., Qu, C., 1994. Simulation of strong seismic motions for the Tangshan earthquake. Earthquake Engineering and Engineering Vibration 14 (3), 1-10, in Chinese.

Xu, X., Deng, Q., 1996. Nonlinear characteristics of paleoseismicity in China. Journal of Geophysical Research 101 (B3), 6209-6231. 
Xu, J., Zhu, G., Tong, W., Cui, K., Liu, Q., 1987. Formation and evolution of the Tancheng-Lujiang wrench fault system: a major shear system to the northwest of the Pacific Ocean. Tectonophysics 134, 273-310.

Yaghmaei-Sabegh, S., Lam, N.T.K., 2009. Ground motion modelling in Tehran based on the stochastic method. Engineering Structures, under review.

Zhu, J.S., 1986. The characteristic of subplate division of crust and upper mantle in the continent of China. Journal of Chengdu College of Geology 13 (1), 75-94, in Chinese. 


\section{Figure Captions:}

Fig. 1. The contour map of crustal quality factor $Q_{0}$ for Eastern China (reproduced from Jin and Aki, 1988) superimposed with the locations of historical earthquake events (as listed in Appendix A). Each contour line is annotated with a $Q_{0}$ value of 200, 400, 600 or 1000. Earthquake events of different magnitude ranges are plotted using different symbols as shown in the legend. The boundaries of the three study regions are also shown.

Fig. 2. Magnitude-distance combinations of each isoseismal as listed in Appendix A. (a) Sino-Korean Paraplatform (SKP) region; (b) Yangzi Platform (YZP) region; (c) South China Fold System (SCF) region.

Fig. 3. $S W V$ profiles of the three selected regions in Eastern China (plotted in logarithmic scale for depths up to $10 \mathrm{~km}$ ). (a) SKP region; (b) YZP region; (c) SCF region.

Fig. 4. Comparison of the $S W V$ profiles of the three selected regions, with those of CENA and WNA. (a) Depths of $1 \mathrm{~km}-10 \mathrm{~km}$ (plotted in logarithmic scale); (b) Depths up to $4 \mathrm{~km}$ (plotted in linear scale).

Fig. 5. Comparison of $M M I$ attenuation relationships (for $\mathrm{M}=7$ ) for the three subregions of Eastern China (without soil site effect). $M M I$ values were converted from $P G V$ values computed by stochastic simulations of the seismological models. The typical crustal thickness of the three study regions, obtained from the global database CRUST2.0, is $31 \mathrm{~km}$. The $Q$ values assumed for this comparison of $M M I$ attenuation relationships are 200 for SKP, 600 for YZP and 350 for SCF estimated based on Jin and Aki (1988). 
Fig. 6. Inferred median site effects and calibrated crustal $Q$ factor (with the associated 90\% confidence limits). (a) SKP region; (b) YZP region; (c) SCF region.

Fig. 7. Comparison of historical $M M I$ values with those simulated by seismological modelling with the calibrated $Q$ factors (corrected for site effects). (a) SKP region; (b) YZP region; (c) SCF region.

Fig. 8. Comparison of simulated $M M I$ attenuation relationships with historical data of 1976 Tangshan earthquake. Noted that distance-dependent $Q$ has a linear $Q-\mathrm{R}$ relationship with $Q$ equals to 25 at $\mathrm{R}=50 \mathrm{~km}$ and increases up to a value of 250 at $\mathrm{R}=$ $500 \mathrm{~km}$.

Fig. 9. Comparison of existing attenuation relationships (Wang et al., 2000) with those simulated by seismological modelling with the calibrated $Q$ factors (rock sites).

Fig. 10. Intra-regional difference: ratio of the attenuation relationships with respect to that of SKP simulated using the seismological models proposed in this study.

Fig. 11. Comparison of velocity response spectra for near-field and far-field events. (a) Near-field event $(M=5.8, R=65 \mathrm{~km})$; (b) Far-field event $(M=7.6, R=330 \mathrm{~km})$. 


\section{Table Captions:}

Table 1. Summary of historical earthquake database used in this study.

Table 2a. The four modelling parameters and the exponent of the profile in Zone II (refer Table 2b) of the three sub-regions.

Table $2 \mathrm{~b}$. Summary of the proposed $S W V$ profiles of the three sub-regions.

Table 3. Summary of median site factors inferred from study of short distance earthquakes $(\mathrm{R}=20-50 \mathrm{~km})$.

Table 4. Summary of $Q$ factors of the three sub-regions.

Table 5. Summary of the seismological parameters of the three sub-regions. 




Fig. 1. The contour map of crustal quality factor $Q_{0}$ for Eastern China (reproduced from Jin and Aki, 1988) superimposed with the locations of historical earthquake events (as listed in Appendix A). Each contour line is annotated with a $Q_{0}$ value of $200,400,600$ or 1000. Earthquake events of different magnitude ranges are plotted using different symbols as shown in the legend. The boundaries of the three study regions are also shown. 


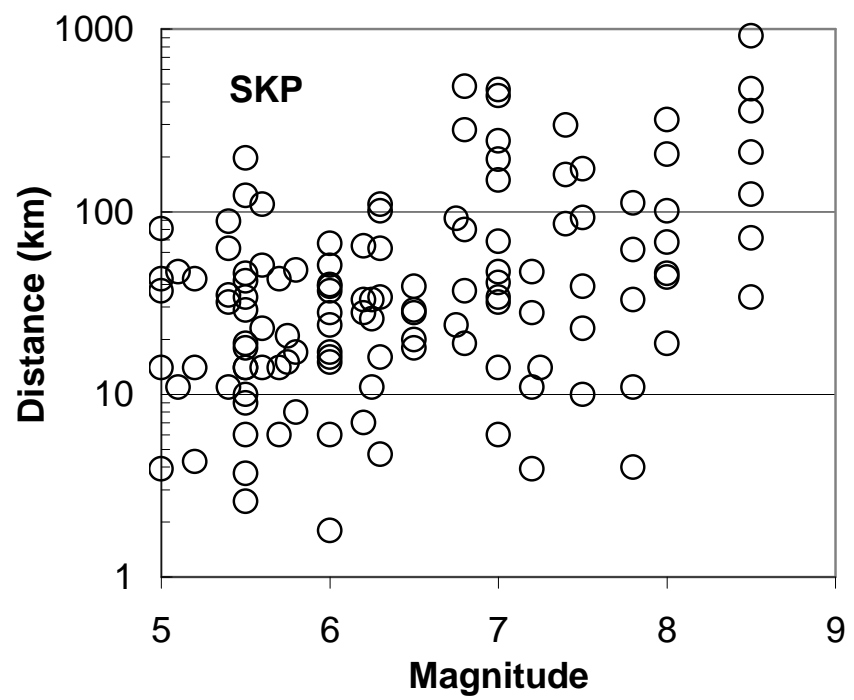

(a) Sino-Korean Paraplatform (SKP) region

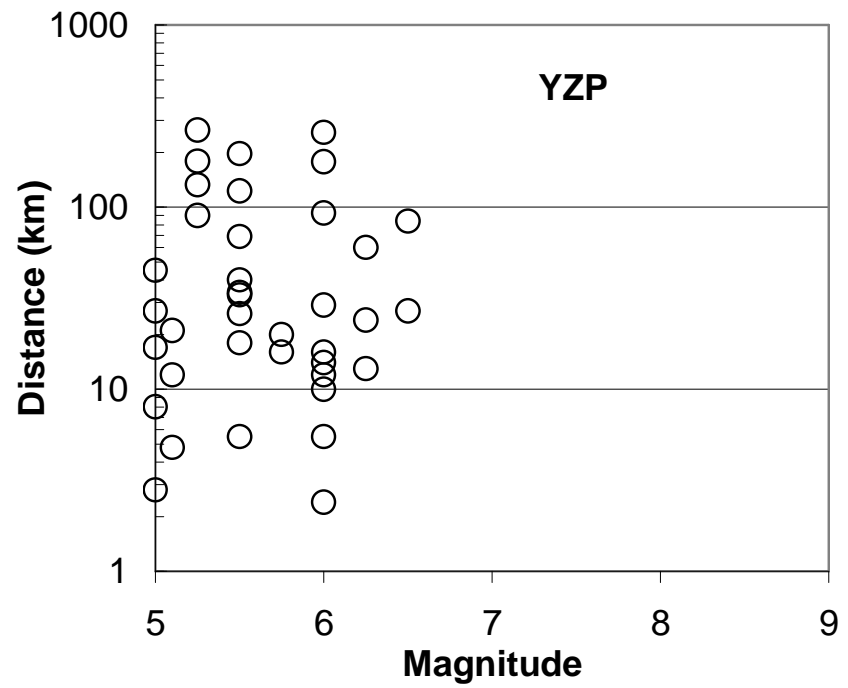

(b) Yangzi Platform (YZP) region

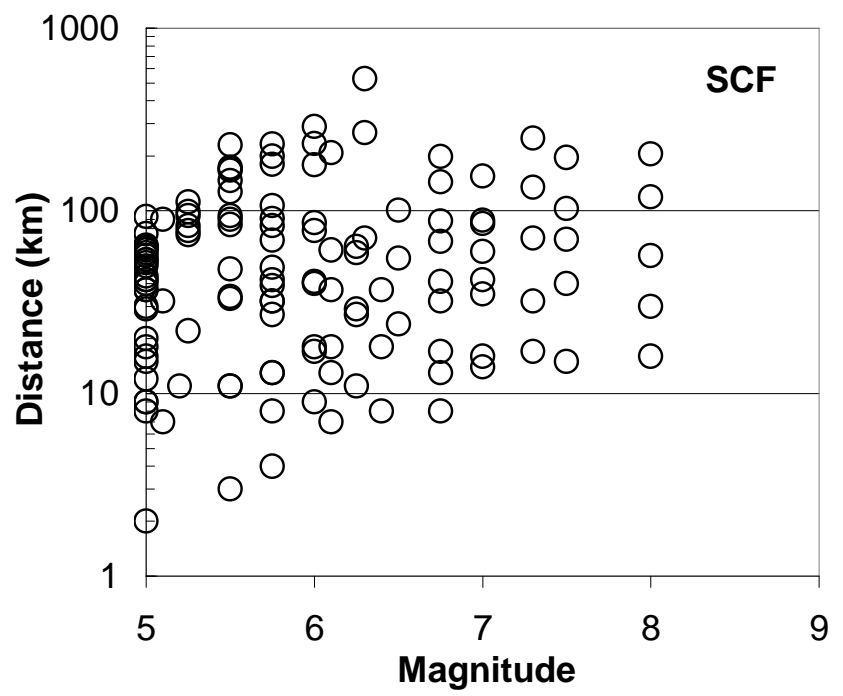

(c) South China Fold System (SCF) region

Fig. 2. Magnitude-distance combinations of each isoseismal as listed in Appendix A. 


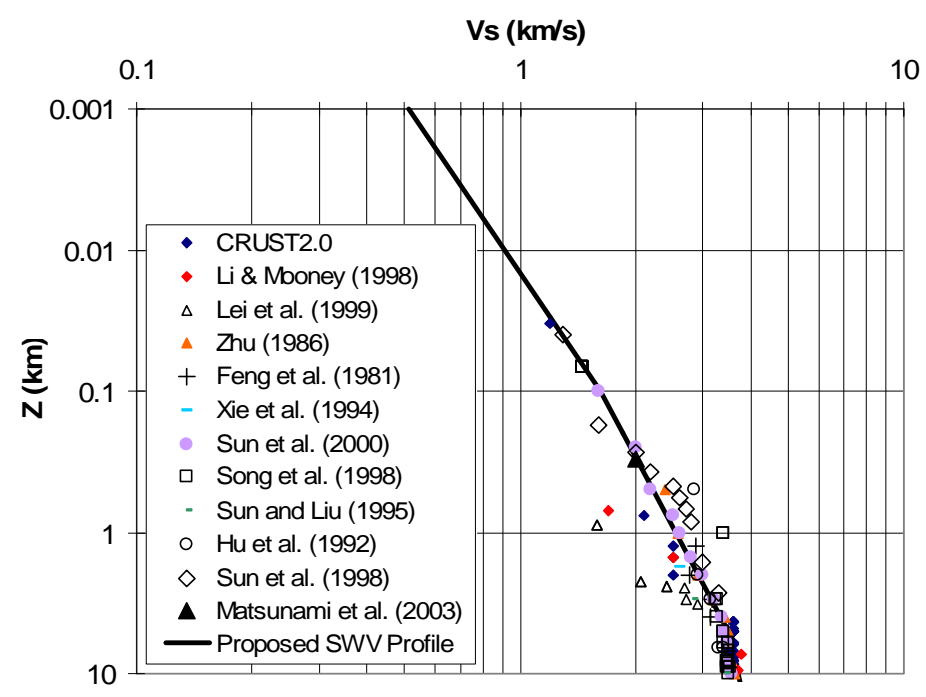

(a) SKP region

Vs (km/s)

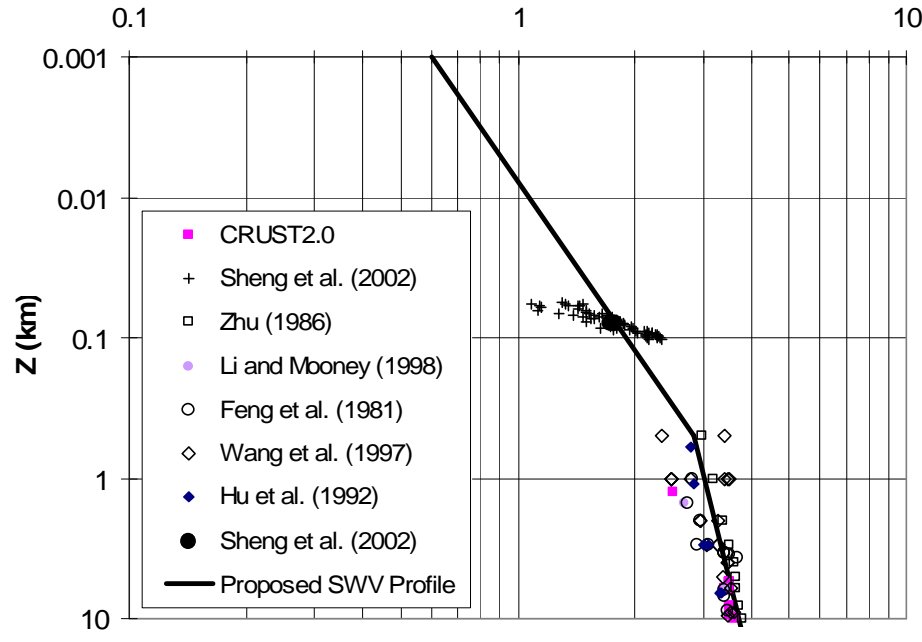

(b) YZP region



(c) SCF region

Fig. 3. $S W V$ profiles of the three selected regions in Eastern China (plotted in logarithmic scale for depths up to $10 \mathrm{~km}$ ). 


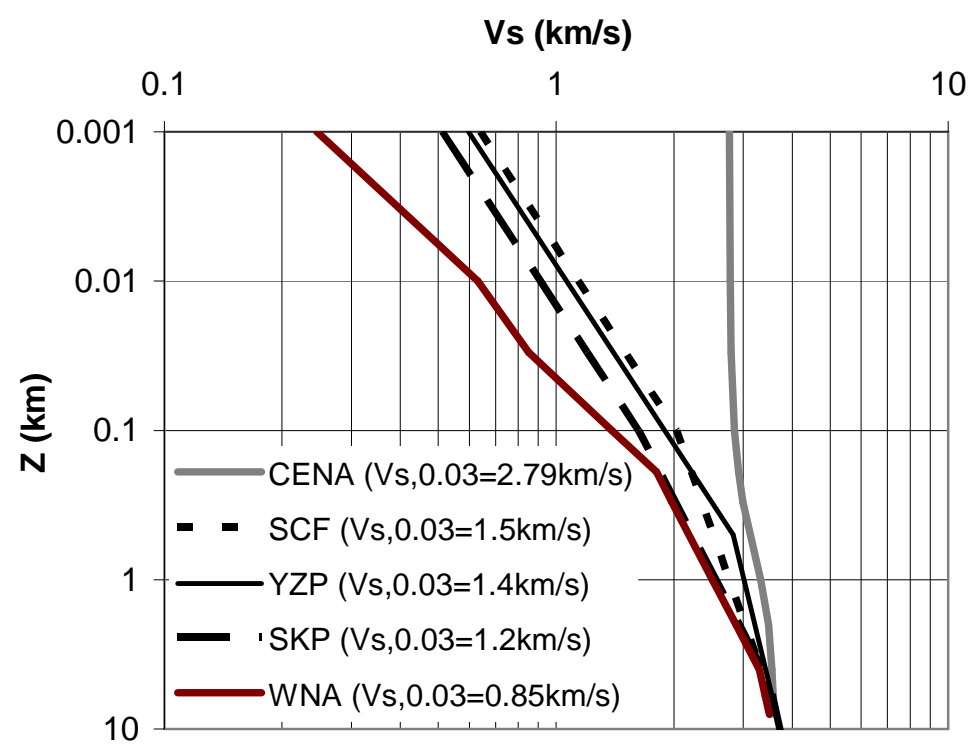

(a) Depths of $1 \mathrm{~km}-10 \mathrm{~km}$

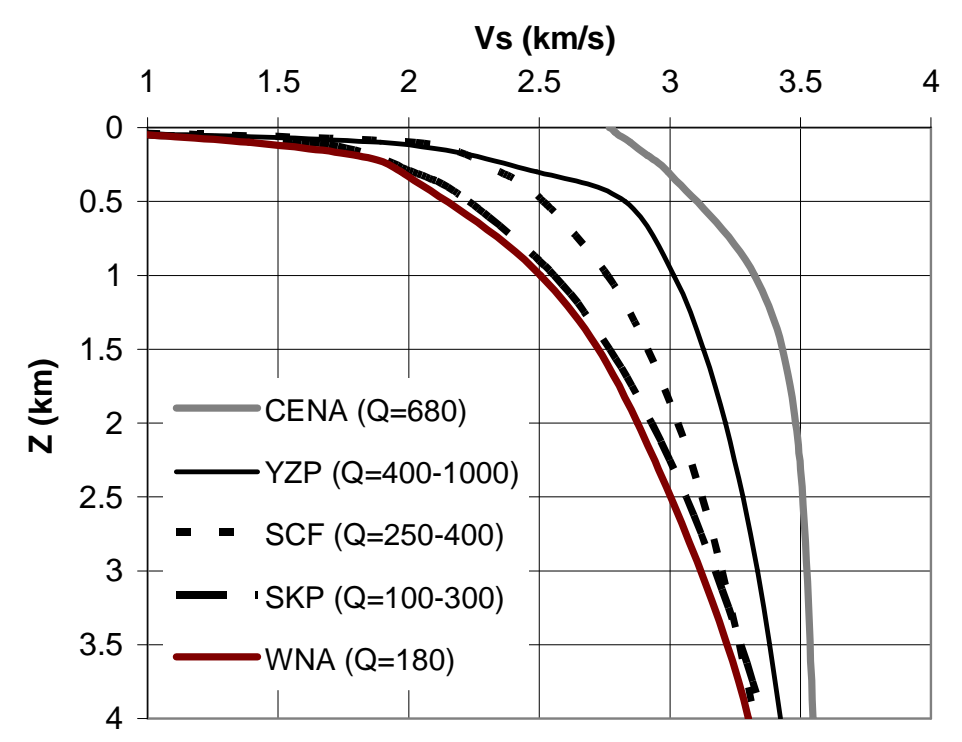

(b) Depths up to $4 \mathrm{~km}$

Fig. 4. Comparison of the $S W V$ profiles of the three selected regions, with those of CENA and WNA. (a) Depths of $1 \mathrm{~km}-10 \mathrm{~km}$ (plotted in logarithmic scale); (b) Depths up to $4 \mathrm{~km}$ (plotted in linear scale). 


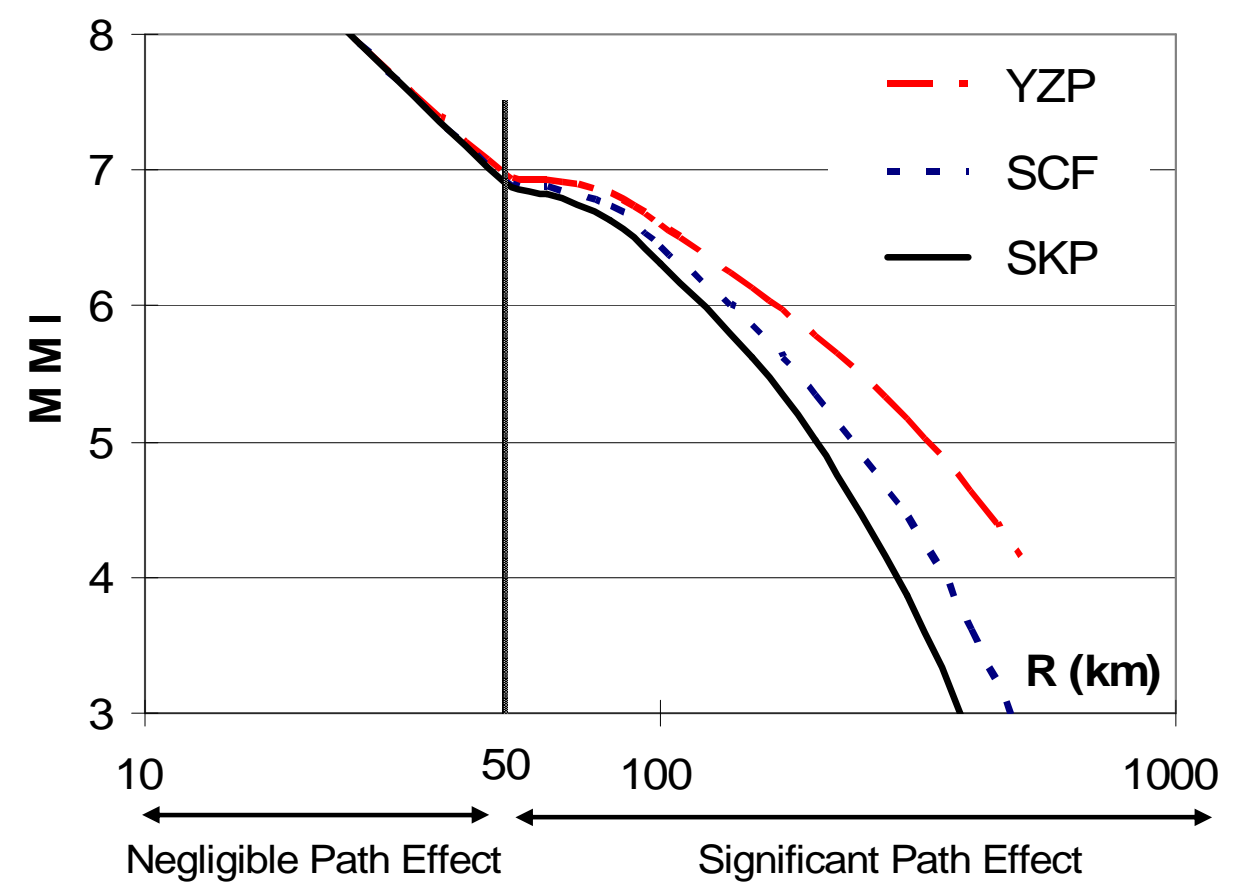

Fig. 5. Comparison of $M M I$ attenuation relationships (for $\mathrm{M}=7$ ) for the three subregions of Eastern China (without soil site effect). $M M I$ values were converted from $P G V$ values computed by stochastic simulations of the seismological models. The typical crustal thickness of the three study regions, obtained from the global database CRUST2.0, is $31 \mathrm{~km}$. The $Q$ values assumed for this comparison of $M M I$ attenuation relationships are 200 for SKP, 600 for YZP and 350 for SCF estimated based on Jin and Aki (1988). 


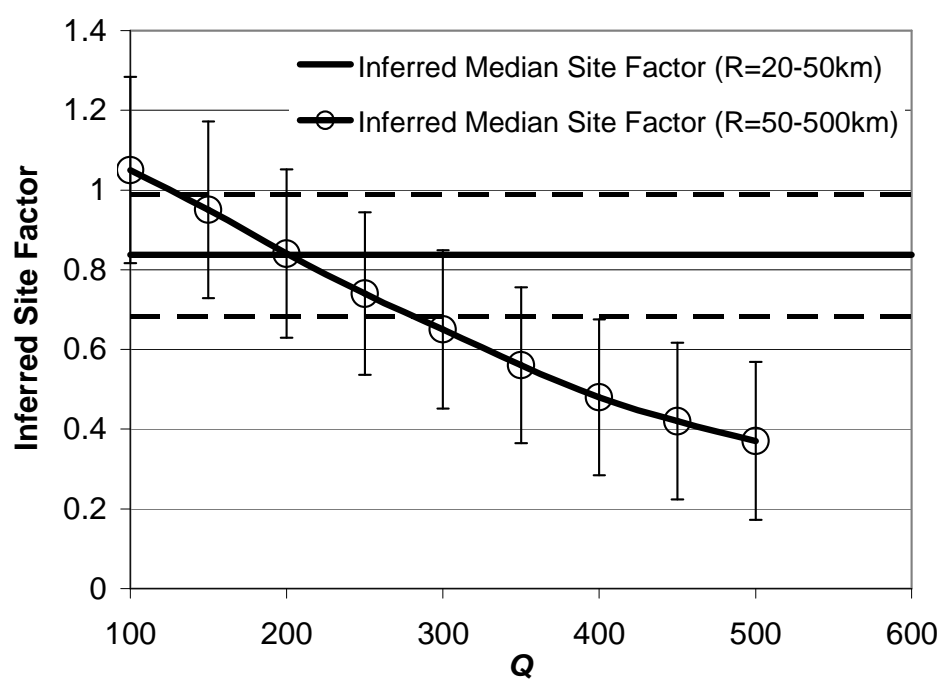

(a) SKP region

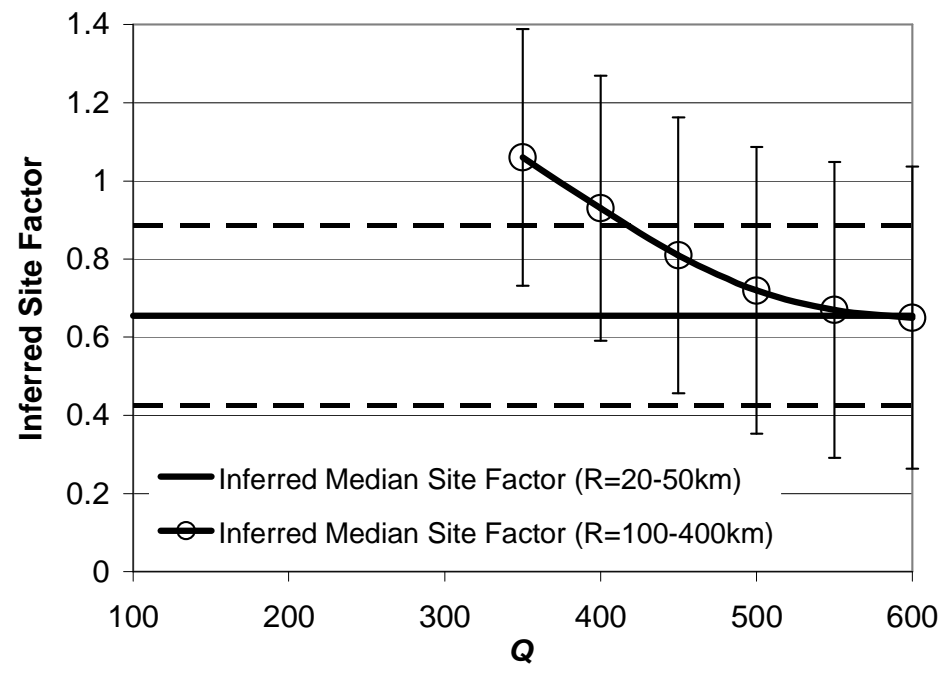

(b) YZP region

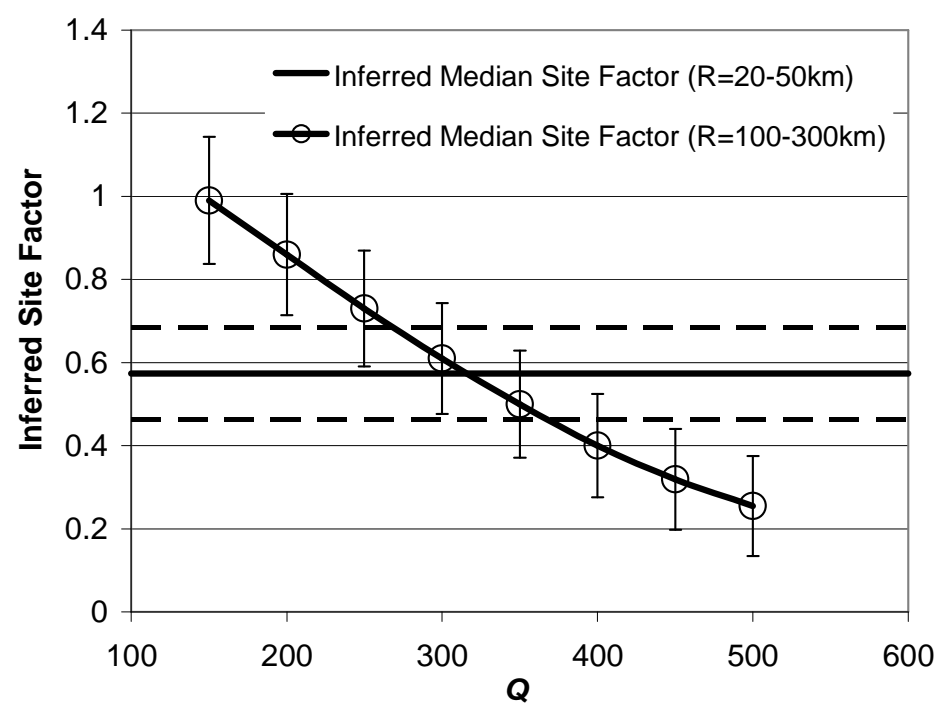

(c) SCF region

Fig. 6. Inferred median site effects and calibrated crustal $Q$ factor (with the associated 90\% confidence limits). 


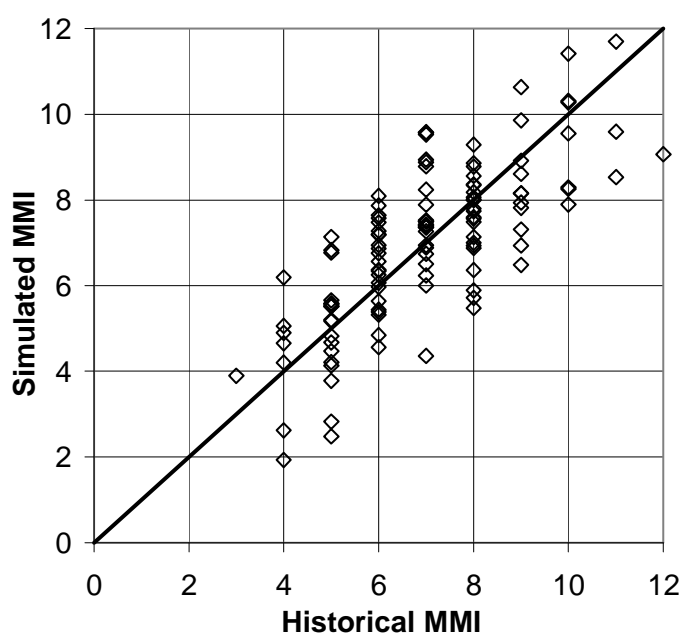

(a) SKP region

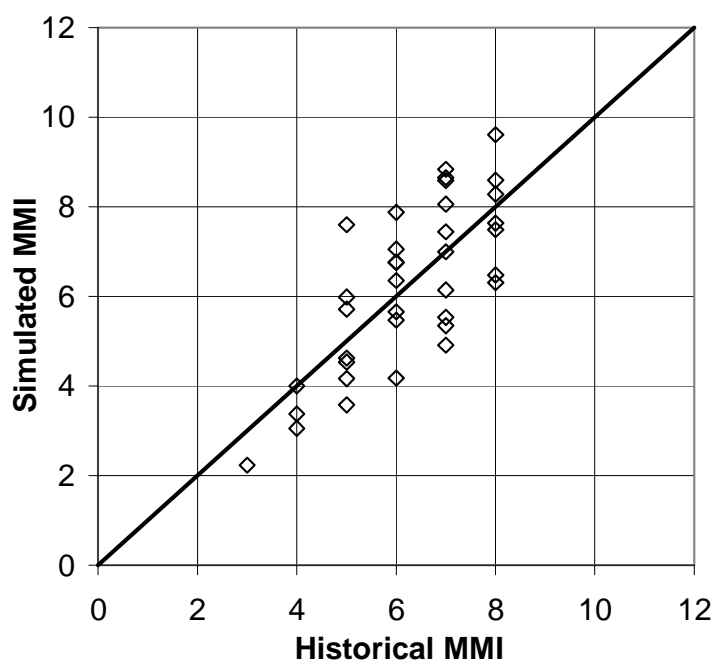

(b) YZP region



(c) SCF region

Fig. 7. Comparison of historical $M M I$ values with those simulated by seismological modelling with the calibrated $Q$ factors (corrected for site effects). 




Fig. 8. Comparison of simulated $M M I$ attenuation relationships with historical data of 1976 Tangshan earthquake. Noted that distance-dependent $Q$ has a linear $Q-\mathrm{R}$ relationship with $Q$ equals to 25 at $\mathrm{R}=50 \mathrm{~km}$ and increases up to a value of 250 at $\mathrm{R}=$ $500 \mathrm{~km}$. 




(a) $\mathrm{M}=5$

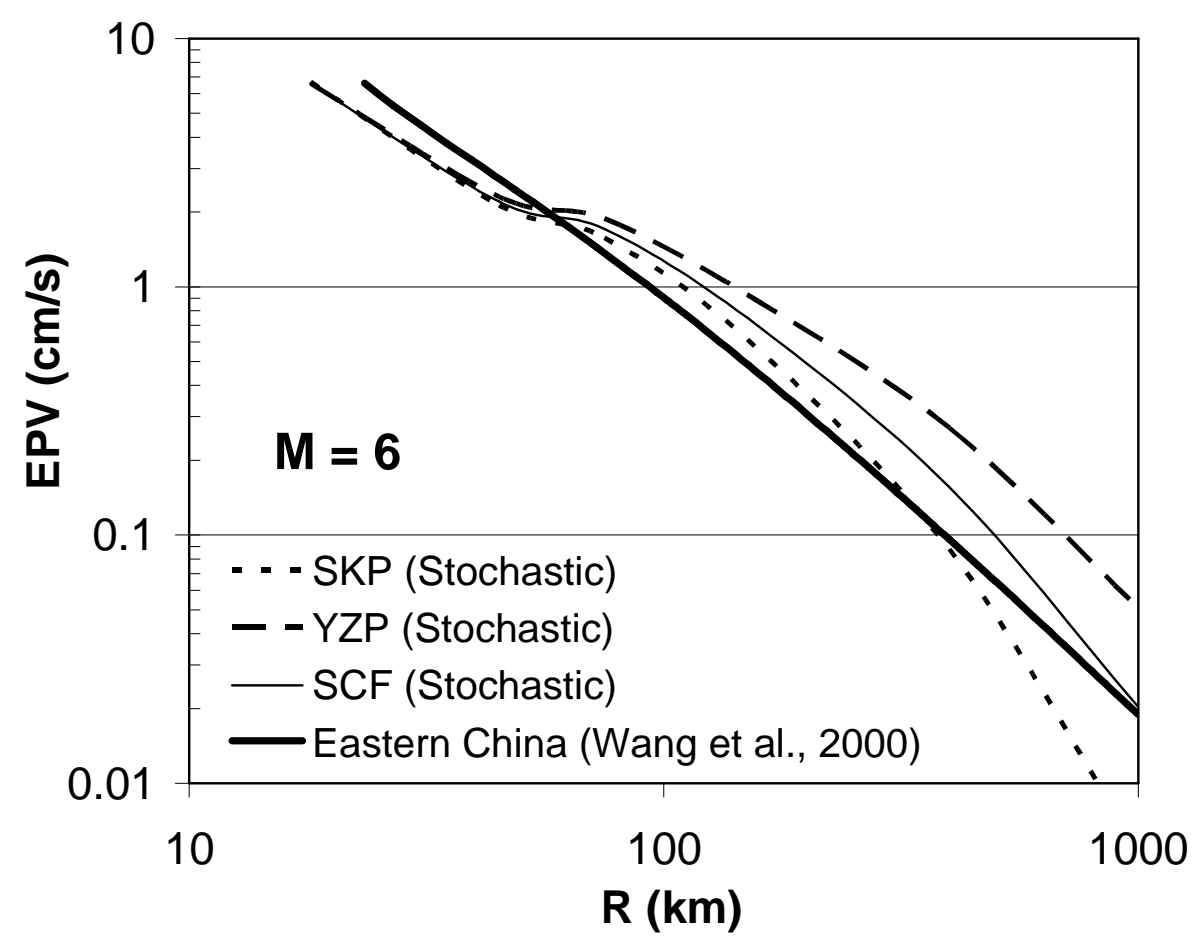

(b) $M=6$ 


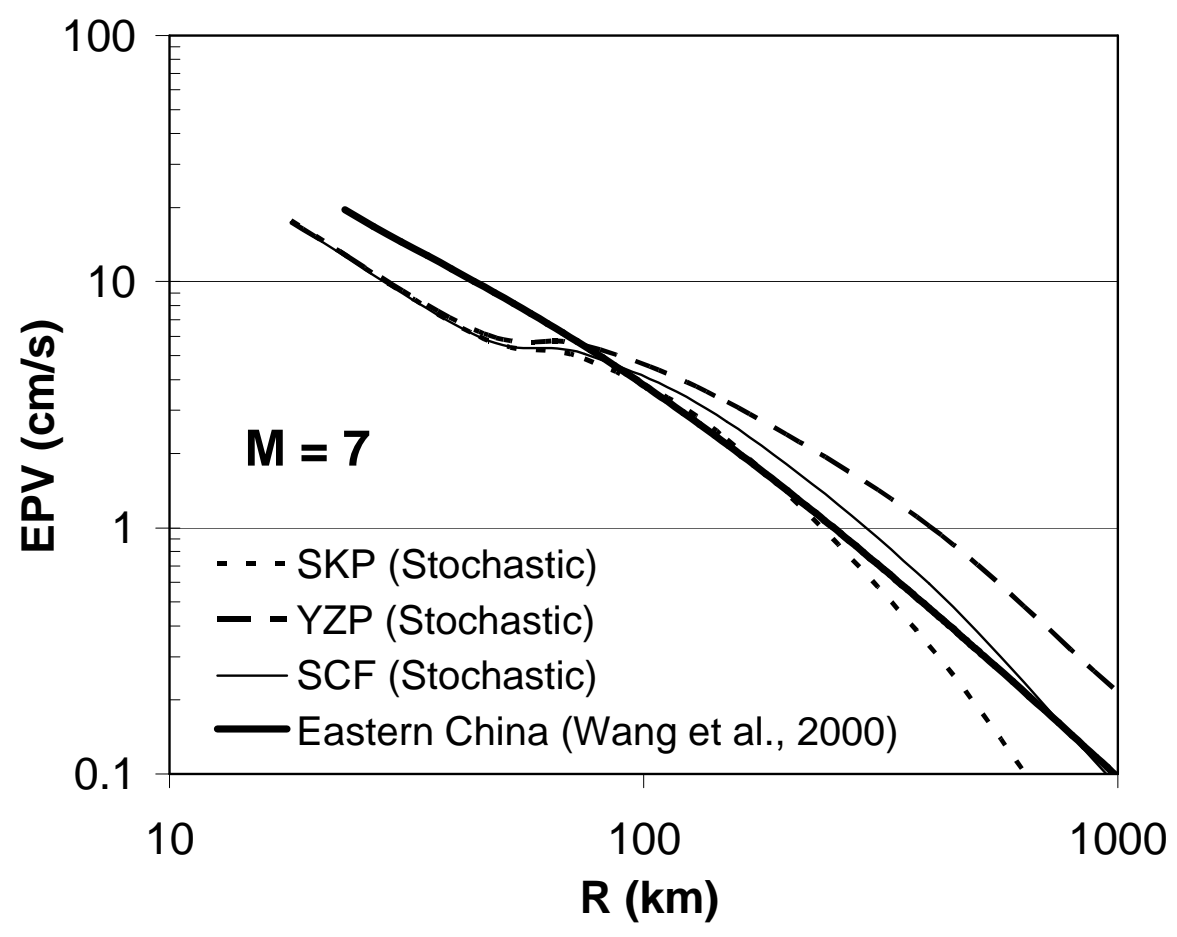

(c) $\mathrm{M}=7$

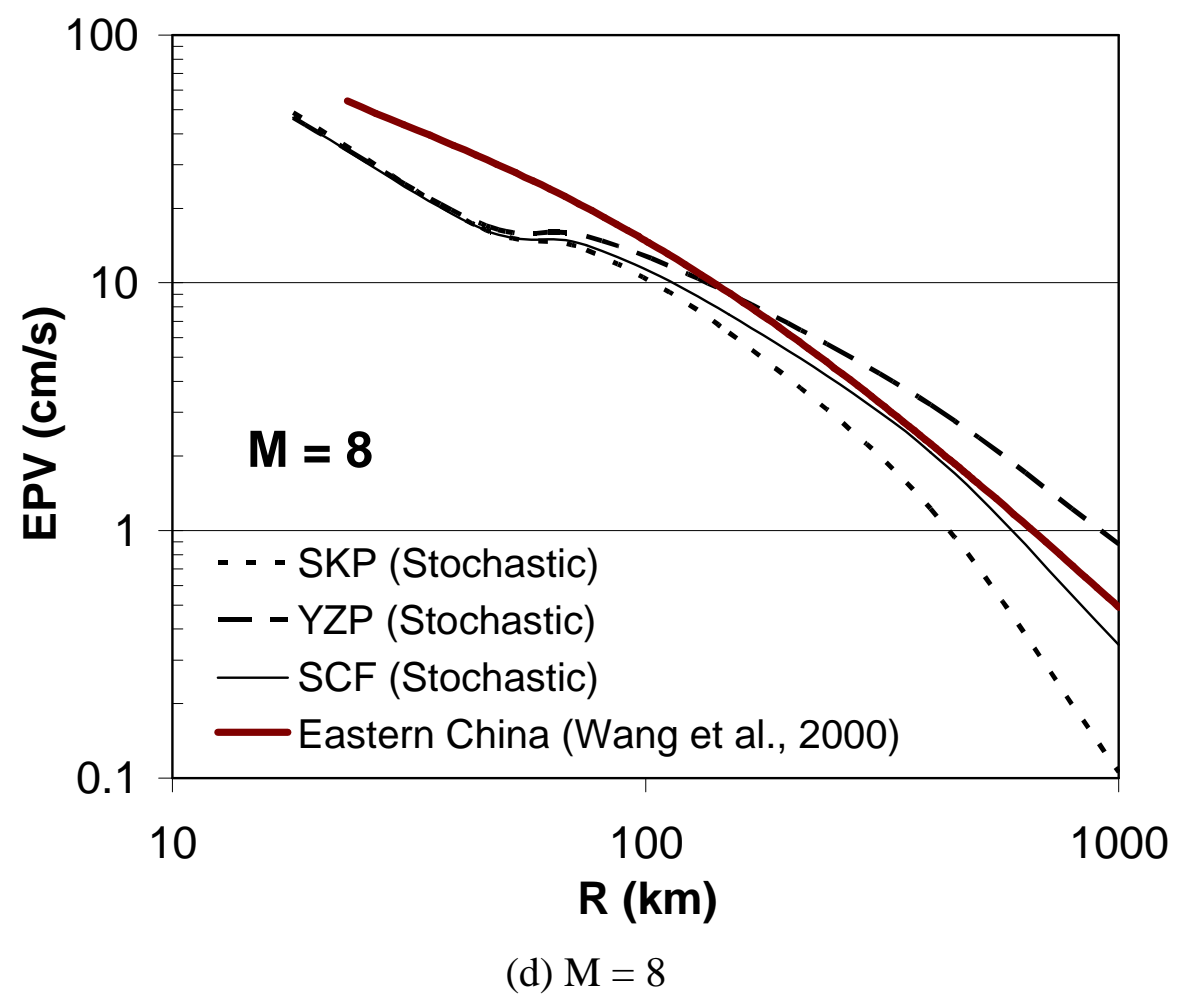

Fig. 9. Comparison of existing attenuation relationships (Wang et al., 2000) with those simulated by seismological modelling with the proposed $Q$ factors (rock sites). 


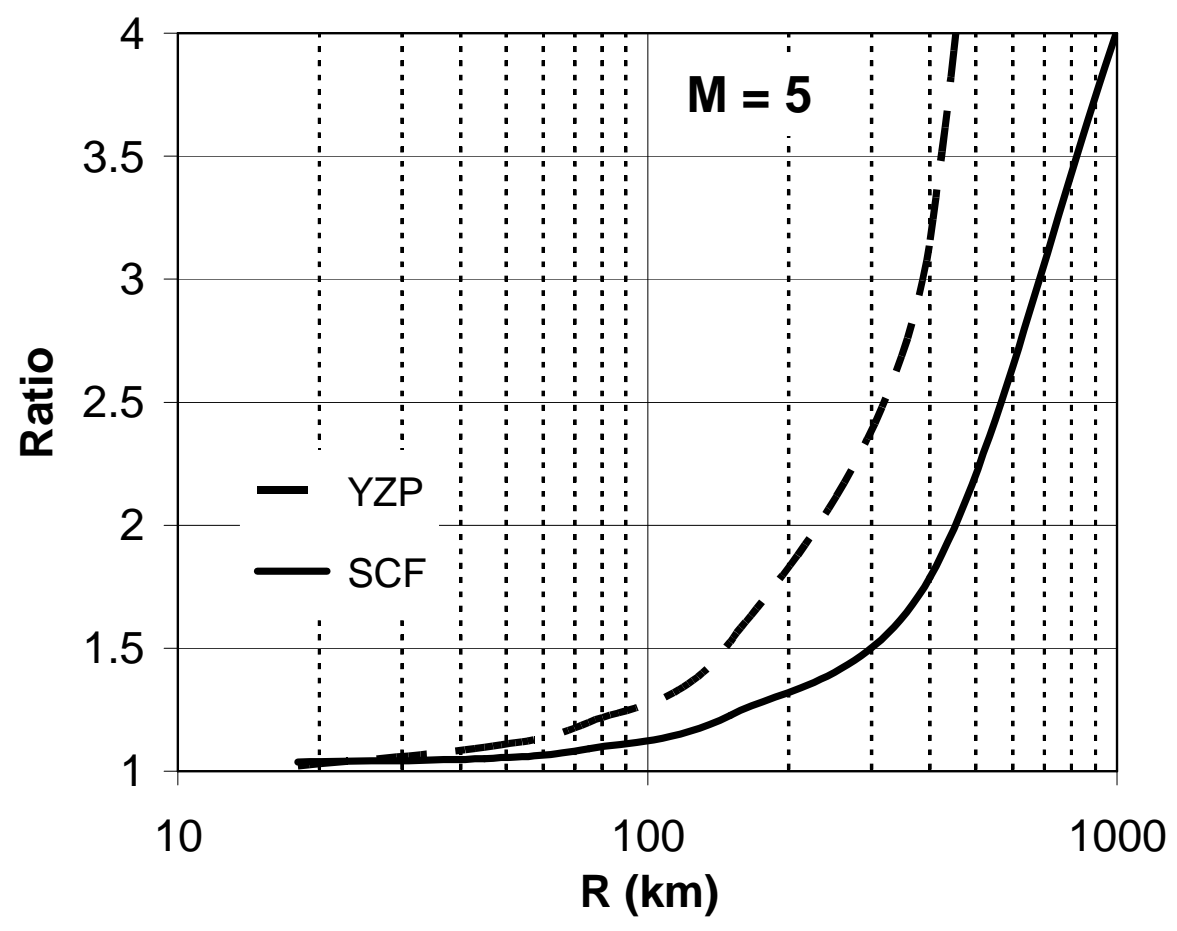

(a) $M=5$



(b) $M=6$ 


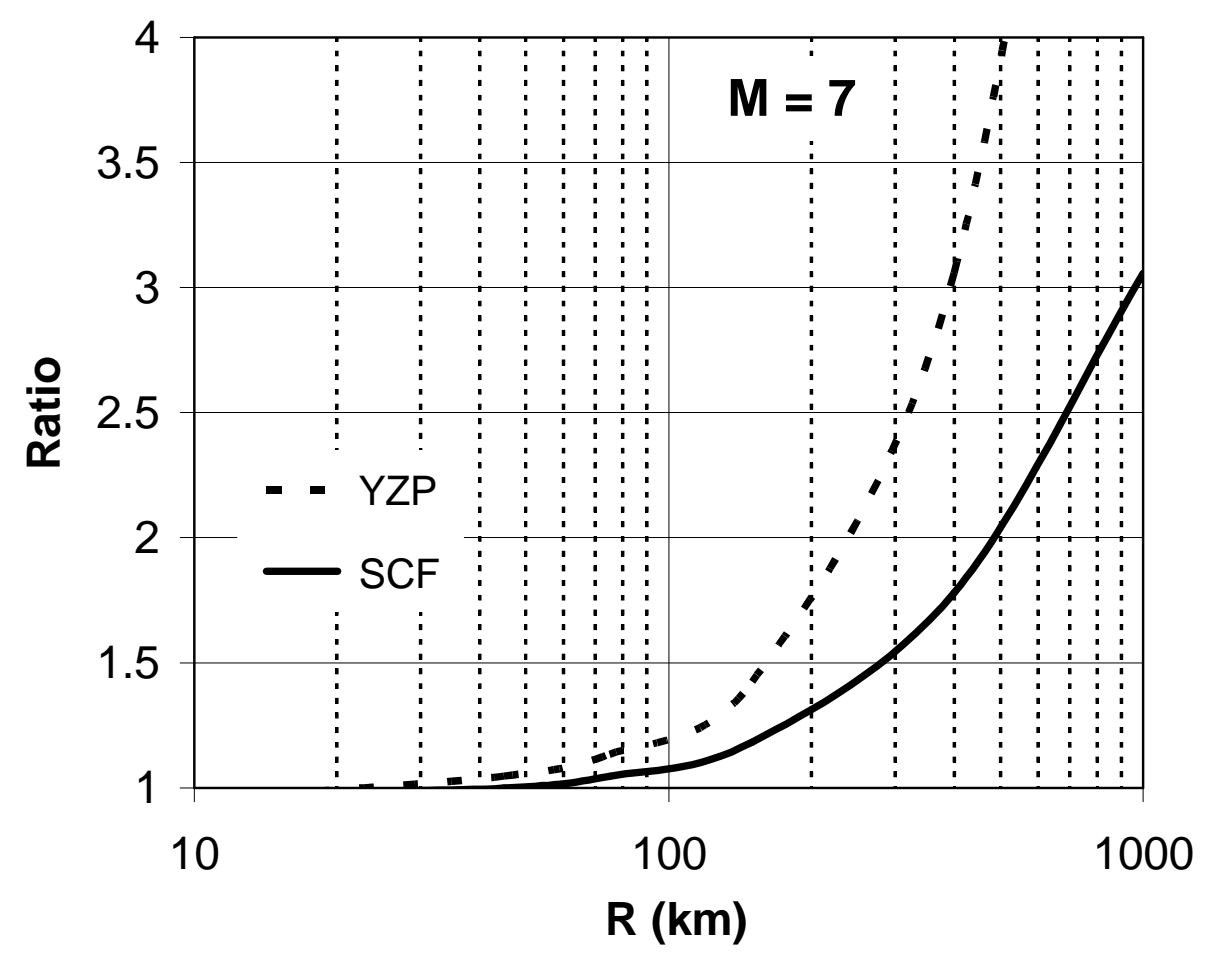

(c) $\mathrm{M}=7$

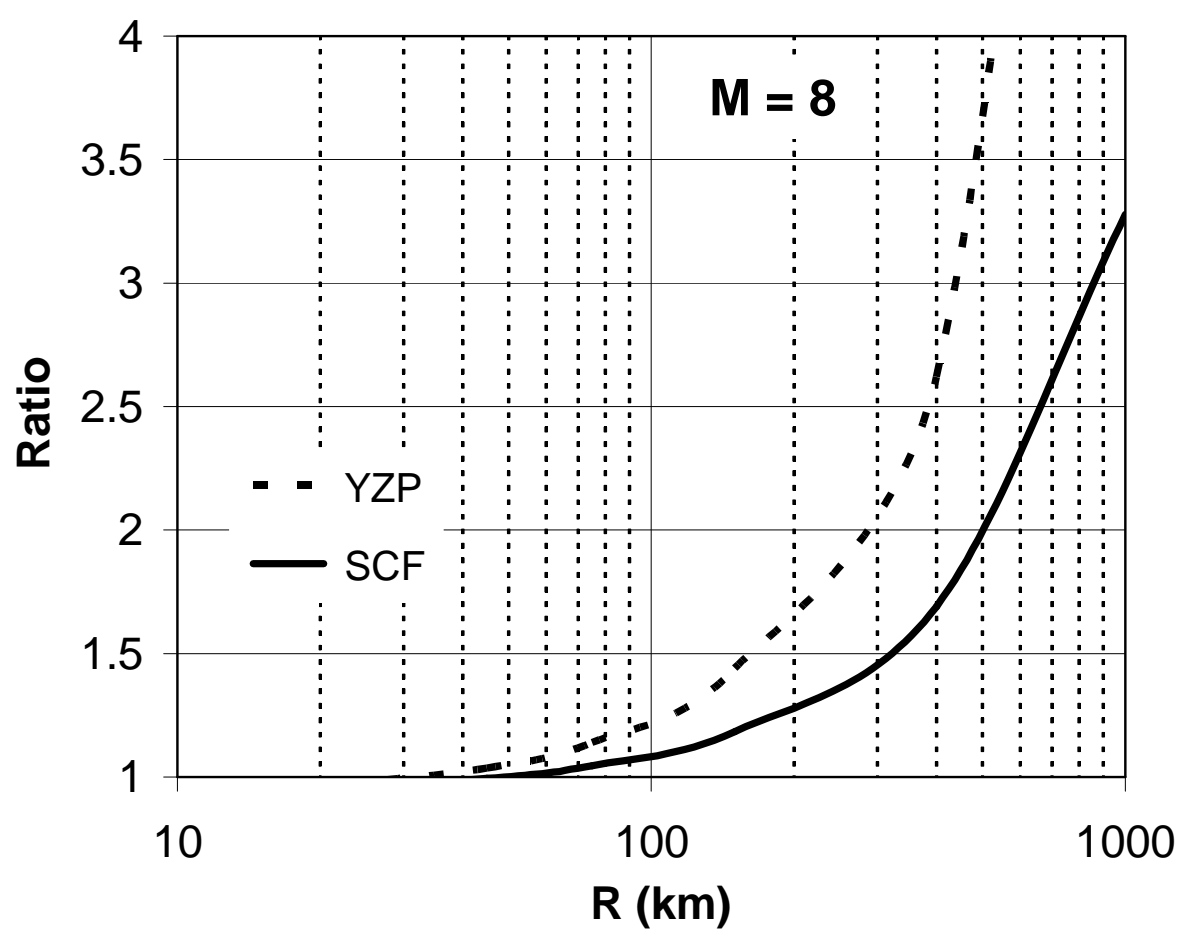

(d) $\mathrm{M}=8$

Fig. 10. Intra-regional difference: ratio of the attenuation relationships with respect to that of SKP simulated using the seismological models proposed in this study. 


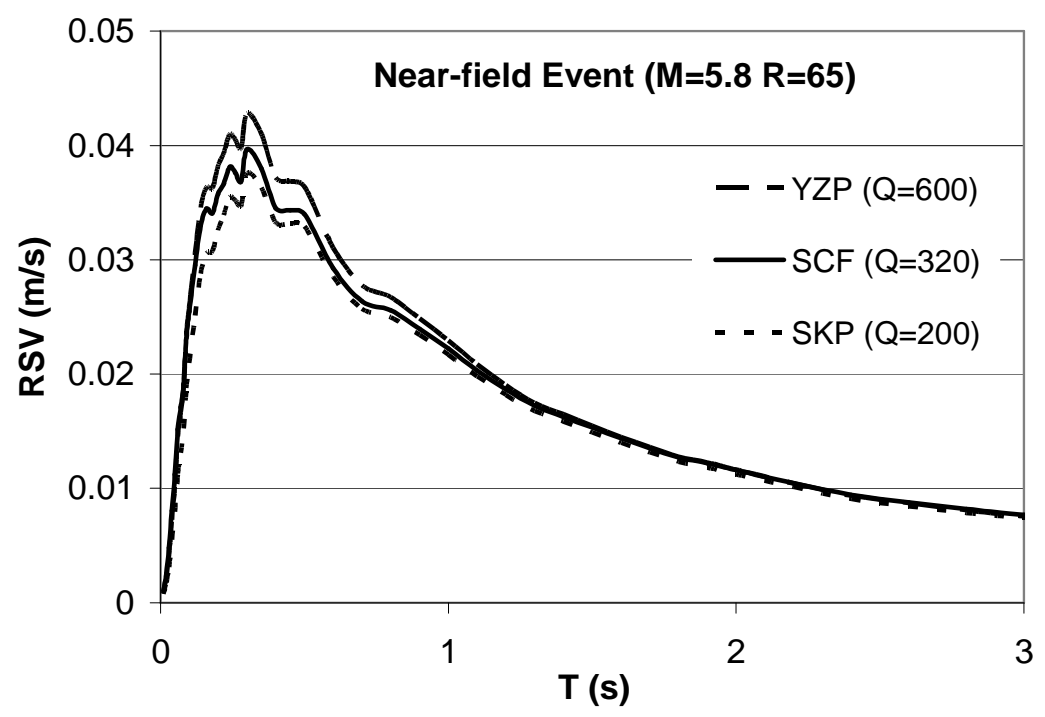

(a) Near-field event $(M=5.8, R=65 \mathrm{~km})$

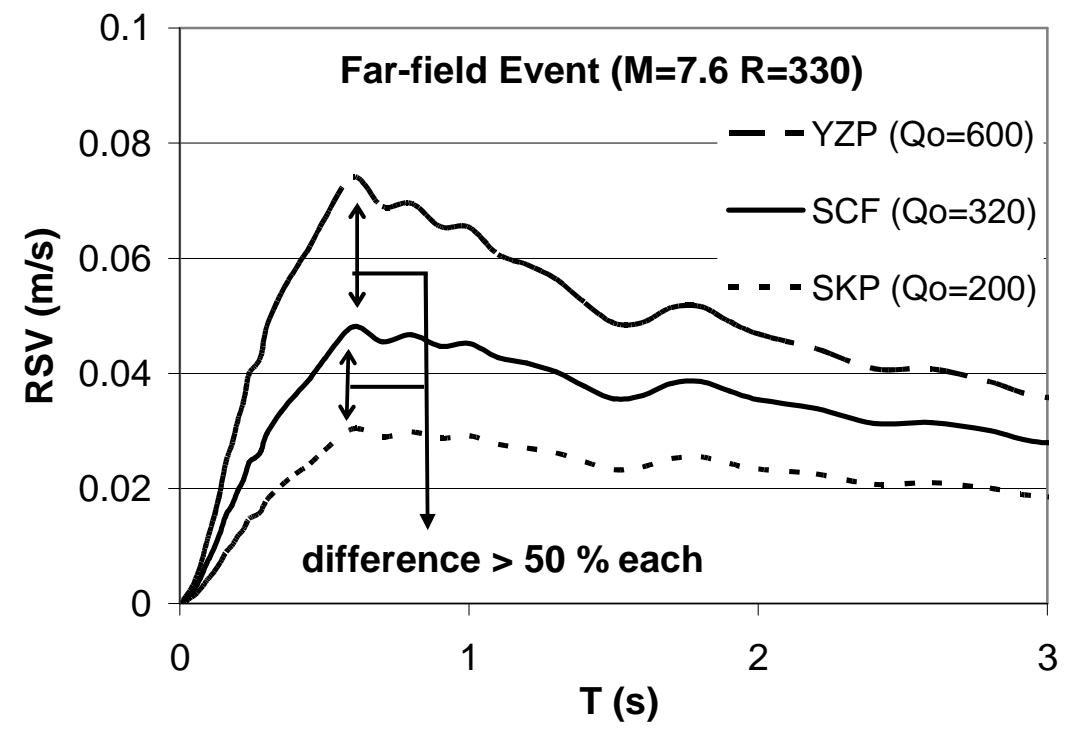

(b) Far-field event $(\mathrm{M}=7.6, \mathrm{R}=330 \mathrm{~km})$

Fig. 11. Comparison of velocity response spectra for near-field and far-field events. 
Table 1. Summary of historical earthquake database used in this study.

\begin{tabular}{lccc}
\hline & SKP & YZP & SCF \\
\hline No. of earthquakes & 53 & 21 & 57 \\
No. of isoseismals & 124 & 38 & 136 \\
\hline
\end{tabular}

Table 2a. The four modelling parameters and the exponent of the profile in Zone II (refer Table 2b) of the three sub-regions.

\begin{tabular}{lccc}
\hline & SKP & YZP & SCF \\
\hline$Z_{s}(\mathrm{~km})$ & 0.1 & 0.5 & 0.1 \\
$Z_{c}(\mathrm{~km})$ & 5.0 & 8.0 & 6.0 \\
$V_{s, 0.03}(\mathrm{~km} / \mathrm{s})$ & 1.20 & 1.40 & 1.50 \\
$V_{s, 8}(\mathrm{~km} / \mathrm{s})$ & 3.65 & 3.65 & 3.60 \\
$n$ & 0.197 & 0.092 & 0.134 \\
\hline
\end{tabular}

Table $2 \mathrm{~b}$. Summary of the proposed $S W V$ profiles of the three sub-regions.

\begin{tabular}{ccccc}
\hline Case & Depth Range & SKP & YZP & SCF \\
\hline Zone IA & $0<Z \leq Z_{s}$ & $1.2\left[\frac{Z}{0.03}\right]^{\frac{1}{4}}$ & $1.4\left[\frac{Z}{0.03}\right]^{\frac{1}{4}}$ & $1.5\left[\frac{Z}{0.03}\right]^{\frac{1}{4}}$ \\
Zone II & $Z_{s} \leq Z \leq Z_{c}$ & $3.51\left[\frac{Z}{5}\right]^{0.197}$ & $3.65\left[\frac{Z}{8}\right]^{0.092}$ & $3.51\left[\frac{Z}{6}\right]^{0.134}$ \\
Zone IIIB & $Z_{c} \leq Z$ & $3.65\left[\frac{Z}{8}\right]^{\frac{1}{12}}$ & $3.65\left[\frac{Z}{8}\right]^{\frac{1}{12}}$ & $3.6\left[\frac{Z}{8}\right]^{\frac{1}{12}}$ \\
\hline
\end{tabular}

Table 3. Summary of median site factors inferred from study of short distance earthquakes $(\mathrm{R}=20-50 \mathrm{~km})$.

\begin{tabular}{cccc}
\hline Sub-region & SKP & YZP & SCF \\
\hline Median site factor & 1.8 & 1.6 & 1.5 \\
& $\left(=2^{0.85}\right)$ & $\left(=2^{0.65}\right)$ & $\left(=2^{0.58}\right)$ \\
No. of data & 68 & 13 & 79 \\
$90 \%$ confidence interval & $1.6-2.0$ & $1.3-1.8$ & $1.4-1.6$ \\
for the median site factor & $\left(=2^{0.85 \pm 0.15}\right)$ & $\left(=2^{0.65 \pm 0.23}\right)$ & $\left(=2^{0.58 \pm 0.11}\right)$ \\
\hline
\end{tabular}


Table 4. Summary of $Q$ factors of the three sub-regions.

\begin{tabular}{cccc}
\hline Sub-region & SKP & YZP & SCF \\
\hline Estimated $Q$ values by Jin and Aki (1988) & 200 & 600 & 350 \\
which Fig. 5 is based upon & $(100-300)$ & $(400-1000)$ & $(250-400)$ \\
Median $Q$ values (and 90\% confidence & 200 & 600 & 320 \\
limits) inferred from calibration (this study) & $(120-280)$ & $(450-600)$ & $(260-360)$ \\
No. of data & 49 & 10 & 51 \\
\hline
\end{tabular}

Table 5. Summary of the seismological parameters of the three sub-regions.

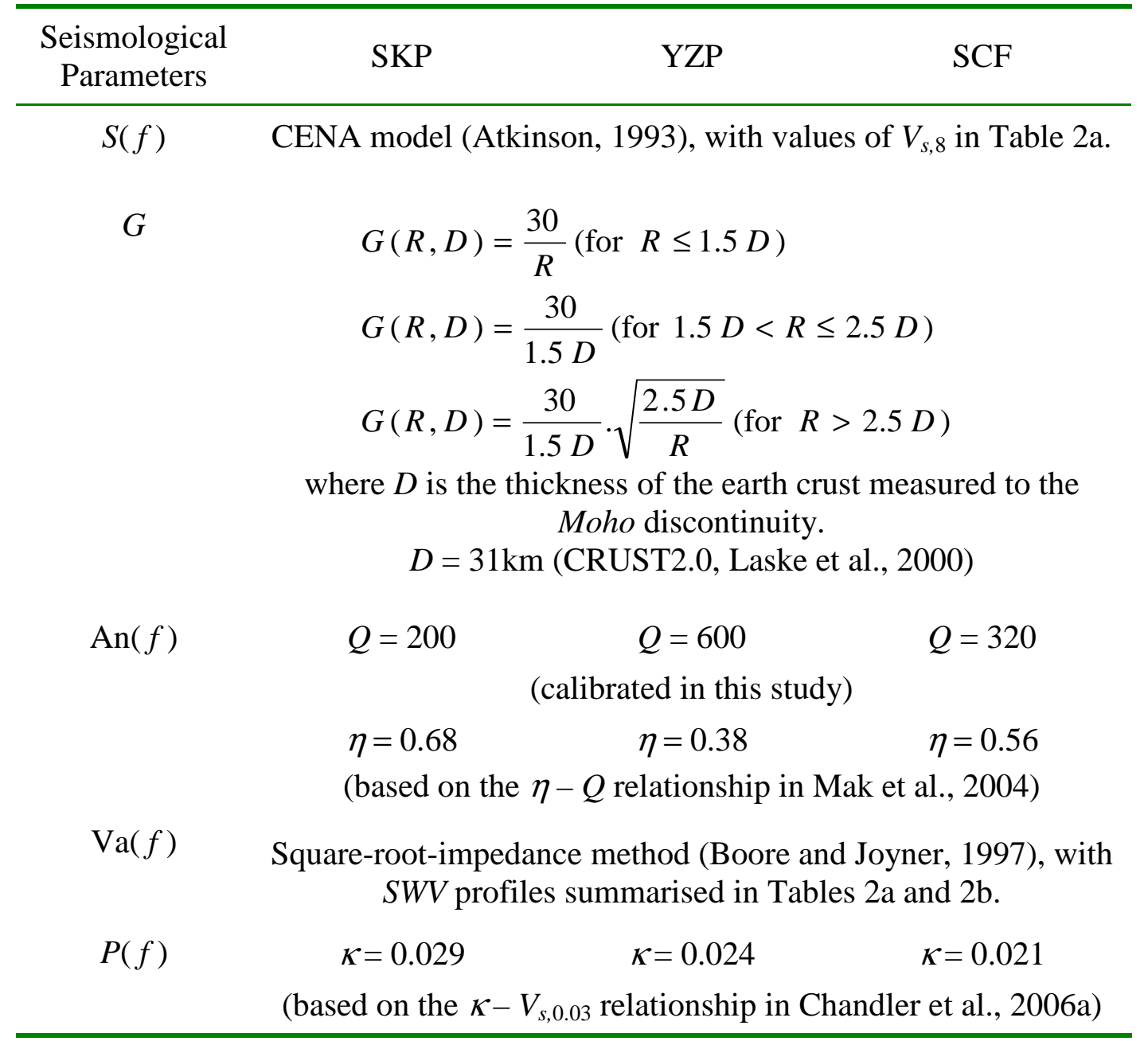

